\title{
Conference proceedings publications in bibliographic databases: a case study of countries in Southeast Asia
}

\author{
Philip J. Purnell ${ }^{1,2}$ (D)
}

Received: 21 April 2020 / Accepted: 22 October 2020 / Published online: 20 November 2020

(C) The Author(s) 2020

\begin{abstract}
Leading citation databases have made concerted efforts to reflect academic conference contributions in the form of proceedings papers in their databases. We studied global trends and a regional case study to determine the relative representation of conference proceedings in the global scholarly literature using the Web of Science, Scopus, and Dimensions. We designed our case study of ten Southeast Asian countries to uncover conspicuous publishing patterns obscured by global average figures. As a result, we discovered that Indonesia alone has made a recent and remarkable shift towards conference proceedings publishing. This trend was not the result of expanding database coverage but may be linked to a rapid increase in conferences locally hosted in Indonesia. The conclusion suggests that conference proceedings are increasingly indexed by major databases, and that scholars might have found advantage in publishing conference papers that were quicker and easier to publish than journal articles or book chapters. Our study is relevant to policy makers in the area of research evaluation because it highlights potential changes in academic publishing behaviour by those being assessed.
\end{abstract}

Keywords Conference proceedings $\cdot$ Indonesia $\cdot$ ASEAN $\cdot$ Location $\cdot$ Promotion

\section{Introduction}

Academic scholars all over the world face mounting pressure to publish their findings in sources that are indexed in global citation databases (Abramo and D'Angelo 2014). Those who evaluate individuals for recruitment, academic promotion, or research grant awards increasingly use some form of quantitative assessment of their publication output and citation impact when taking decisions. The methods used in such assessment are often the subject of extensive discussion (Hicks, Wouters, Waltman, de Rijcke and Rafols 2015) and frequently use established citation indexes such as Web of Science (WoS) and Scopus (Archambault, Campbell, Gingras and Lariviere 2009) and more recently, new databases

Philip J. Purnell

p.j.purnell@cwts.leidenuniv.nl

1 Centre for Science and Technology Studies, Leiden University, P.O. Box 905, 2300 AX Leiden,

The Netherlands

2 United Arab Emirates University, Al Ain, UAE 
such as Dimensions (Hook, Porter, and Herzog 2018). All these databases comprise research contributions published in a variety of academic sources, most importantly journals, books and conference proceedings.

The subject of this study is the body of literature resulting from scholarly conferences and which play an important and increasingly visible role in the scholarly literature alongside journal articles, book chapters and other forms of scientific communication. In recent years, conference proceedings have been integrated with citation indexes to enable academics to search, retrieve and cite them in the same way they cite journal articles. The contribution of conference papers to the major citation indexes has not yet been well documented and this is the first topic addressed in this study.

Global trends hide lots of interesting dynamics at the level of individual countries and as the second topic addressed by our paper, we include a case study comprising the ten countries of the Southeast Asian Nations (ASEAN). The ASEAN countries provide a good case study for this topic because they hold a shared vision of identity along with similarities in geography and scientific goals.

Each country displayed a different pattern in conference proceedings output which were grouped into 4 clusters, and the discussion presents some possible reasons for the differences. Such reasons include database coverage, the influence of national policy on the behaviour of scholars, and the location of the conference.

In this article, we review the literature on the developing role of conference proceedings in scholarly communication, their incorporation into the major citation databases, and introduce the ASEAN region as an ideal case study. In the methods section, we describe the databases used, the Web of Science, Scopus, and Dimensions and how we accessed their data. The results and discussion is organised into an initial section in which we present the trends in conference proceedings paper publishing over the last 20 years in each of the databases and how their numbers and proportions of the databases compare with one another. We then present data for the ASEAN region and its ten countries and group them into 4 clusters based on their conference proceedings publishing patterns. The results for Indonesia were so striking that the final part of the study examines two possible explanations for the sharp increase in conference output. First, whether the growth was due to expansion in database coverage, and the second is whether the location of the conference was related to the number of resulting proceedings papers from the hosting country. The article concludes that conference proceedings have become increasingly visible in the major citation databases, that interesting country-level patterns can be revealed by analysis, and that there has been a steep growth in preferential conference paper publishing in Indonesia coinciding with an increase in locally hosted conferences.

\section{Literature review}

\section{Conference proceedings}

An evolutionary model of scholarly communication was described several decades ago in which academic research is communicated first as personal correspondence and in subsequent incremental forms that include open letters, conference proceedings and finally the journal article (Garvey, Lin, Nelson and Tomita 1972a). A detailed study on the publication behaviour of 12,000 scientists over a 5 year period demonstrated that the majority of conference material presented at national meetings in America 
was later published as a journal article (Garvey, Lin, Nelson and Tomita 1972b) and this pattern became broadly accepted as common practice in the exchange of scientific information between researchers. Later evidence challenged this view with conference proceedings seen by some as an end product and being accepted as evidence of scholarly activity by university tenure and promotion committees (Drott 1995), rather than being merely a step on the way to a journal article.

The advent of the Internet spawned fundamental changes to communication of academic research findings with some results appearing on the web before they were published in journals or as conference proceedings (Goodrum, McCain, Lawrence and Giles 2001). Work comparing conference papers with journal articles showed that conference papers are generally shorter (Gonzalez-Albo and Bordons 2011), less cited (Drott 1995) than journal articles and their citation peak is shorter lived (Lisée, Larivière and Archambault 2008). In many fields assessment for promotion gives higher weighting to journal articles, which serves as an incentive for scholars to adapt conference proceedings for subsequent journal submission. However, in other fields proceedings papers and journal articles are seen as different expressions of the same work (Bar-Ilan 2010) revealing a variance in publication behaviour between fields.

There is broad variance in the relative importance of proceedings papers depending on the field of study. One study showed that roughly half the papers in ISI Proceedings-the first conference proceedings database and later known as the Conference Proceedings Citation Index (CPCI) - were assigned to the field of Engineering and that this share increased from 43 per cent in 1994 to 61 per cent by 2002 (Glänzel, Schlemmer, Schubert and Thijs 2006), more than 6 times the corresponding share found in the Web of Science (WoS) journals. In the same study, the proportion of proceedings papers classified in the field of physics grew from 25 per cent to 32 per cent over the 8 year period while the corresponding proportion of journal articles in the WoS remained stable at around 13 per cent. Similarly, the engineering field was singled out as one in which proceedings papers receive a higher proportion of citations indicating that conference material is of greater import than in other fields (Lisée, Larivière and Archambault 2008). This was especially the case for computer science papers.

Computer science has also been identified as a field in which conference proceedings are a major venue (Bar-Ilan 2010) for disseminating research findings. Bar-Ilan (2010) pointed out that conference papers from Lecture Notes in Computer Science (LNCS) were already indexed in the Science Citation Index before the addition of the CPCI to the WoS in 2008. In a study comprising interviews with authors and journal editors in the software engineering field, conference papers were thought to be shorter than journal articles and contain only the exciting part of the study intended to keep a specialized audience abreast of novelties in their field (Montesi and Owen 2008). Journal articles were found to be a more mature product designed to enable readers to replicate results and form part of an archive. Furthermore, conference papers were often reworked and later published as journal articles. An extensive study of citations to non-WoS literature in 3 social science fields showed that only $2 \%$ of cited references to academic literature outside the WoS were to conference papers in psychology, only $1 \%$ in political science and even less in economics (Nederhof, van Leeuwen and van Raan 2010) showing very limited influence of non-WoS literature on highly cited works. 


\section{Databases}

The WoS originally comprised 3 journal indices; the Science Citation Index Expanded (SCIE), Social Sciences Citation Index (SSCI) and the Arts \& Humanities Citation Index (A\&HCI) each consisting of metadata from academic peer reviewed journals. Where conference proceedings were published in journals in these indexes the papers were labelled as both 'article' and 'proceedings paper'. A Dutch study concluded in 2007 that it was feasible to expand the WoS to include additional conference papers to provide better coverage in the field of computer science provided some technical issues were addressed such as the treatment of different versions of the same study (Moed and Visser 2007). In 2008, Thomson Reuters merged the content from its ISI Proceedings Science and Technology database into the WoS and renamed it the conference proceedings citation index (CPCI). Although a limited number of conference proceedings were already published in journals indexed in the database, it was the incorporation of the CPCI that contributed the majority of the conference literature to the WoS. It was this addition of conference proceedings into the Web of Science in 2008 that provided an opportunity to study these papers as a unique source of scholarly material.

At about the same time, journal articles that had been adapted from meeting presentations had their document types changed from 'paper' to 'proceedings paper', the same name given to the majority of the publications in the CPCI. All documents indexed from conference material were thus assigned the document type 'proceedings paper' although they may have originated either as journal articles that made explicit reference to initially having been presented at a scientific meeting or may instead have been published in a 'book' of proceedings. Proceedings papers published in journals have been found to vary in their proportion with respect to regular articles by field with highest proportions found in computer science/information technology and applied physics (Zhang and Glanzel 2012). Conference proceedings in journals can be further categorized into those accepted in ordinary issues and those published as special editions or monographs. Those published in monographs have been found in library and information science to be shorter, have fewer references, pass more quickly through peer review and receive fewer citations (GonzálezAlbo and Bordons 2011).

These nuances in publication behaviour, changes in documentation types and evolution of the WoS coverage over time mean that any study of publications is susceptible to an element of misinterpretation of the results owing to the idiosyncrasies of the database. For this reason, 3 databases were used; WoS, Elsevier's Scopus that was released in 2004 as a more inclusive citation index, and Dimensions launched in 2018 by Digital Science. The changes in proportions of conference proceedings by different countries over time might be partially explained by the natural expansion of any single database over time. By using three databases, we are likely to illuminate the effects of any major changes in conference proceedings coverage by any one database.

Elsevier launched its proprietary citation index, Scopus, in 2004 which now covers more journals than Web of Science (Mongeon and Paul-Hus 2016). However, the overlapping coverage of conference proceedings between WoS and Scopus is limited. Indeed, WoS appears to cover many conference proceedings that are not indexed in Scopus, and Scopus covers many proceedings not covered by WoS (Visser, Van Eck and Waltman 2019).

Dimensions, a relative newcomer to citation indexing, was launched in early 2018 and offers a free version including access to just over 100 million scholarly records. Users can identify around 6 million conference proceedings among the records without requiring an 
organizational subscription. Dimensions relies heavily on Crossref as the backbone of its data (Hook et al. 2018). Dimensions coverage is also comparable with Scopus, indeed at least $90 \%$ of Scopus indexed papers were found in Dimensions with the exception of the most recent year in which coverage dropped to about two-thirds (Thelwall 2018) probably due to a longer time lag in indexing in Dimensions. Many Scopus indexed conference proceedings are however absent in Dimensions (Visser et al. 2019).

The different databases do not always coincide on their coverage and definition of document types, for instance Anne-Wil Harzing found that Dimensions indexed more of her conference papers than Scopus while the WoS indexed none of them (Harzing 2019). The document type definitions are not always uniform as Dimensions classifies all items indexed from journals as articles while the WoS and Scopus separates conference proceedings, editorial material, book reviews, letters, corrections, and others as specific document types. For instance, we observed in this study that Dimensions classified more than 100,000 Journal of Physics Conference Series papers as journal articles, which the WoS and Scopus consider conference proceedings. These practices all swell the number of journal articles in Dimensions which in turn makes the proceedings content seem a smaller proportion.

This indicates the coverage practices of the WoS, Scopus and Dimensions are independent of each other, and that multiple databases should be used whenever possible to build a picture of the real situation without relying too heavily on any single database.

\section{ASEAN region}

Publishing behaviour is subject to universal forces such as the requirement for academics to publish their work and demonstrate some form of impact. Regional differences in publication behaviour can provide an interesting basis for more specific study, for example the fast-growing emerging regions such as those of South East Asia where 10 countries, Brunei Darussalam, Cambodia, Indonesia, Laos, Malaysia, Myanmar, Philippines, Singapore, Thailand and Vietnam, have formed the ASEAN group of nations. The organization was founded in 1967 (ASEAN 2019) in order to promote peace, collaboration, regional research, and common social, cultural and economic values.

The ASEAN countries provide an ideal case study because they share a common geographical region region, and have shared scientific goals. They have all rapidly increased their scientific output in recent years and it is interesting therefore to observe whether publication patterns emerge at individual country level that are obscured by global trends. Othere studies have used the ASEAN countries for similar reasons.

In 2011, Nguyen and Pham studied the scientific output and impact of the ASEAN countries and described 4 distinct groups with Singapore alone in the most advanced bloc, Malaysia and Thailand in the second, Indonesia, The Philippines and Vietnam in the third, and finally Brunei, Cambodia, Laos and Myanmar making up the fourth cluster (Nguyen and Pham 2011). These researchers also found correlations between scientific output and both the Knowledge Index and the Knowledge Economy Index published by the World Bank in 2008 (Chen and Dahlman 2005) each of which confirmed the four distinct groups of ASEAN countries observed by Nguyen and Pham. The rate of economic growth of countries such as Singapore has been linked to the investment in research and development (R\&D) (Nguyen and Pham 2011). A large 40-country study of investment and publication data demonstrated a positive correlation between $R \& D$ spending and research publication output (Meo, Al Masri, Usmani, Memon and Zaidi 2013). 
As part of a UNESCO report, Moed and Galevi described a bibliometric model to group 25 Asian countries' relative stage of development by organizing them into 3 clusters based on the proportion of their internationally co-authored papers and the geographical location of the collaborating countries (Moed and Halevi 2014). The first group includes only Singapore among the ASEAN countries and whose papers were often co-authored with researchers in China, Hong Kong and Macau. The second cluster also only features one ASEAN country, Malaysia, which is more linked to research groups in India, Pakistan and Iran, while the third group contains the remaining members in a South East Asian cluster. These authors also draw a link between the state of a country's development and the ratio of the number of its doctoral students to the number of its publications. For example, Japan, a developed country has roughly the same number of doctoral students as Indonesia but produces 100 times the number of publications as Indonesia (Moed and Halevi 2014). This paper built on the idea of organising the countries into clusters based on their conference proceedings publishing behaviour.

\section{Methods and data sources}

The method followed for analysing conference proceedings followed the same pattern for each database. First, publications were extracted from the databases and organised by document type and country. Proceedings papers were compared with all document types to determine the proportion of conference papers published by authors in each country. The second step was to analyse the patterns from each of the ten ASEAN countries and group them into 4 broad clusters based on distinctive publishing behaviour. Finally, the findings were validated through personal knowledge of database indexing, and interviews with a conference organiser in Indonesia, and an international publisher of conference proceedings.

Data for the bibliometric studies was extracted from in-house versions of the WoS, Scopus and Dimensions databases hosted by CWTS at Leiden University. The CWTS version of WoS comprises 5 citation indices; the Science Citation Index Expanded (SCIE), Social Sciences Citation Index (SSCI), Arts \& Humanities Citation Index (A\&HCI), Conference Proceedings Citation Index-Science (CPCI-S) and the Conference Proceedings Citation Index-Social Sciences \& Humanities (CPCI-SSH) and is collectively referred to as WoS 5-ed meaning five editions. Neither the Book Citation Index (BkCI) nor the Emerging Sources Citation Index (ESCI) were included in the study because they are not hosted in the system. The extraction includes records up to the end of 2019, which allows fairly reliable study of all years up to and including 2018. The data for 2019 was not complete and therefore results for that year are not presented in the study. The in-house version of the WoS database hosted by CWTS is extracted multiple times every year from the database provider and subject to an extra round of cleaning, address unification and data validation. Scopus data were extracted in May 2019 and Dimensions data in June 2019 with the expectation that data for all years up to 2018 would be reliable enough to use in the study.

These stable and accurate versions of the databases are therefore more suitable for bibliometric study than the online versions that are designed for immediate reflection of the most recently indexed papers. Therefore, the interface versions of these databases will necessarily show slightly different results than those presented in this study.

The papers used in this study were those with document types 'proceedings paper' and 'proceeding' from Scopus and Dimensions respectively, and all papers in the CPCI for 


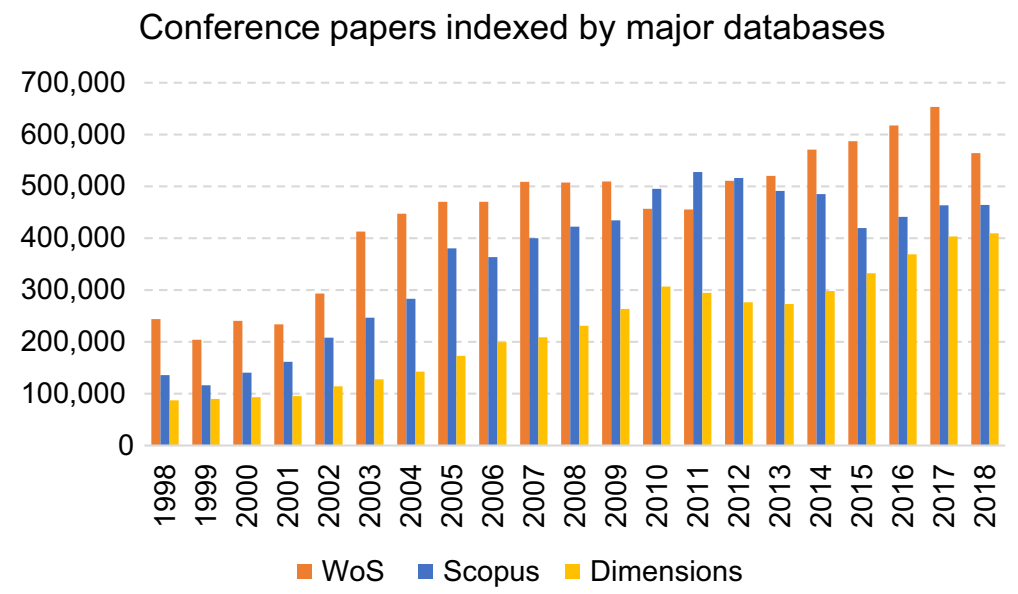

Fig. 1 Conference papers in citation indexes

WoS. In each case, the proportion of conference papers was defined as the number of conference papers divided by the total output. The total output means the entire database for Scopus and Dimensions, while for WoS it means the three journal indexes plus the 2 conference proceedings indexes, known as WoS-5ed.

To determine Indonesia's rank in conference output, we used author affiliations on the proceedings papers and noted Indonesia's position. We browsed the conference series publisher websites to determine the location of the conferences and listed the proportion of conferences that were hosted in Indonesia. For this section we used only the WoS and Scopus but not Dimensions because the conference series could not be reliably identified from the in-house version of the database.

\section{Results and discussion}

\section{Conference proceedings in citation indexes}

As the databases have grown, the number of conference proceedings records has generally increased over time (Fig. 1). Looking back 20 years we can see that WoS usually indexed between 20-40\% more conference papers each year than Scopus, although the WoS surge in 2003 increased the gap to $67 \%$ and the Scopus surge in 2005 closed the gap again to $23 \%$. In the subsequent 3 years, 2010-12 the number of conference papers in the WoS dipped and was overtaken by Scopus which continued its rise to a peak in 2011 . The conference paper indexing in WoS then increased again whilst Scopus fell back and the difference between the 2 databases in 2015-17 stabilised at about 40\%. The 2018 figures showed a drop in WoS conference papers, although these might still change as records are belatedly indexed. The conference papers indexed in Dimensions appeared to be independent of WoS and Scopus growing at a slower rate and usually totalled between $50-62 \%$ of the Scopus papers until 2015. In the 4 years to 2017, Dimensions added conference papers at a rate of 9-11\%, far higher than WoS and Scopus. 


\section{$\%$ Conference papers}

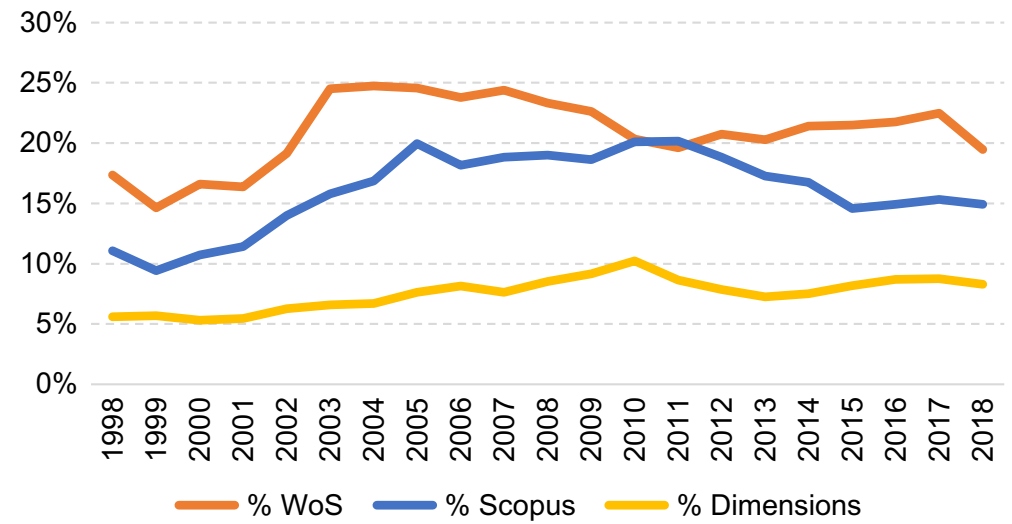

Fig. 2 Conference papers in WoS

The number of conference proceedings records in the WoS was fairly even until 2001 in line with the rest of the WoS as demonstrated by the stable proportion of conference papers in the WoS (Fig. 2). Thereafter followed a steep increase of conference records, 77\% growth between 2001 and 2003. This growth was faster than the rest of the WoS database and resulted in conference papers contributing an increasing proportional share of the database that rose from 16 to $25 \%$ in those 2 years. In the subsequent 14 years the number of conference records in WoS grew only $58 \%$ and its proportion of the database reduced and stabilized at around $21 \%$.

Tracking the share of conference papers in WoS, Scopus and Dimensions showed that over the past 20 years, WoS has consistently indexed a higher proportion of conference papers than the other 2 databases. The only exceptions were in the year 2005 when a peak of Scopus-indexed conference papers came close to the WoS share, and in the years 2010-11 when the proportion of conference papers in Scopus briefly surpassed that in the WoS. The share of conference papers in WoS reached its lowest point since 2002 in 2011 which coincided with the highest peak in Scopus. Dimensions consistently contained a lower share of conference papers than both the established databases.

\section{Regional trends in the ASEAN countries}

The second part of the study focussed on the specific trends observed in the 10 countries of the ASEAN region. As global figures are the average of all the world's regions, it might be possible to uncover more interesting patterns by looking at individual countries. The ASEAN countries have the stated aim of working together on scientific research and provided an appropriate set of countries for study.

Results are first presented for the region as a whole and subsequently for the individual countries. We looked within the country-level findings to try to cluster countries together that exhibited similar conference proceedings publishing patterns. For instance, countries which showed increased conference output to a greater extent than the regional trend could be clustered together, while those countries whose conference publishing declined would be another cluster. A third cluster was for countries which followed the regional trend, and 
yet a fourth was for countries whose output was too low to assign to any other cluster with confidence.

The conference proceedings output from the ASEAN region started in the WoS and Scopus fairly late and from a very low base and therefore this paper focusses on those published in the last 10 full years plus 2018. Data for 2018 were included as almost complete but not completely reliable at the time of analysis. Therefore, the 2018 figures are included to provide insight into the latest trends but we also go back 10 full years prior to 2018 to ensure we covered a full decade of complete data.

A comparison of ASEAN conference proceedings between WoS, Scopus and Dimensions (Fig. 3) demonstrated some similarity with the global pattern, specifically the higher proportions of conference papers in the WoS and the lowest share in Dimensions. The share of conference papers in Scopus exceeded that of WoS only in 2010-11 and this was by a greater margin than we saw in the global graph. Individually, each of the ten countries in the ASEAN region demonstrated a different pattern and we attempted to group these patterns into four clusters as described above.

\section{ASEAN country clusters}

The number of conference papers published by authors in the ASEAN region and their proportion of overall publications has been diverse, with each country at first glance seeming to display its own unique pattern of growth (Figs. 4,5,6,7,8,9,10,11,12,13). Upon closer inspection, it was possible to group the 10 patterns into 4 clusters.

The first cluster included Indonesia and the Philippines because their patterns (Figs. 6 and 10) were both characterised by steep growth in the share of conference proceedings papers relative to other document types. The proportion of conference papers published by authors in the Philippines (Fig. 6) has approximately doubled since 2012 in each of the 3 data sources. The publishing output from the Philippines has increased in that time across all document types, however the conference output has increased more quickly. The case of Indonesia is even more remarkable (Fig. 10) since the share of conference papers has reached $80 \%$ in the WoS and 58\% in Scopus. Contrary to expectations, the growth was not reflected at all in the Dimensions data which showed output of conference papers and journal articles growing at almost exactly the same rate and more recently the conference proceedings and book chapters losing some share to journal articles. In the WoS and Scopus databases, the expansion in the share of conference papers was clearly at the expense of journal articles, and in Scopus also of book chapters.

The second group included only Singapore, whose share of conference papers among its output has consistently fallen (Fig. 11) in all 3 data sources over the past 10 years. The conference paper output was fairly flat for Scopus and Dimensions for the entire period, whilst there was a sustained period of growth in the WoS for a 5 year period from 2011 to 2016 before the output fell back again. Therefore, as the output of other document types has grown, the share of conference papers has steadily declined in each database studied. In the Scopus database, the decline in conference paper share was taken up mainly by journal articles as book chapters also saw a decline. Meanwhile in Dimensions, the book chapters dropped less, and the journal articles took up the share. These figures did not demonstrate any major shift in publishing behaviour and were most likely due to an acceleration of journal article publishing with which conference output simply did not keep pace.

The third group comprised three countries; Malaysia, Thailand, and Vietnam, each of which generally followed the patterns seen at global level. This pattern was characterised 
ASEAN conference papers

40,000

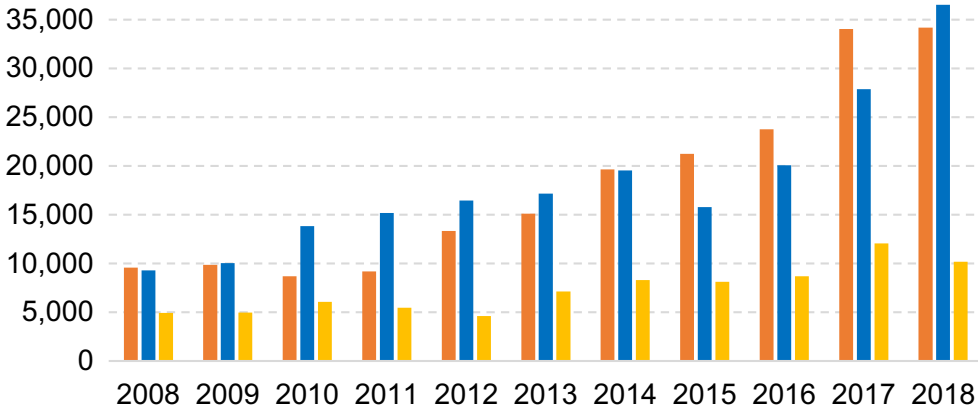

-WoS $\backsim$ Scopus Dimensions

ASEAN - conference papers share

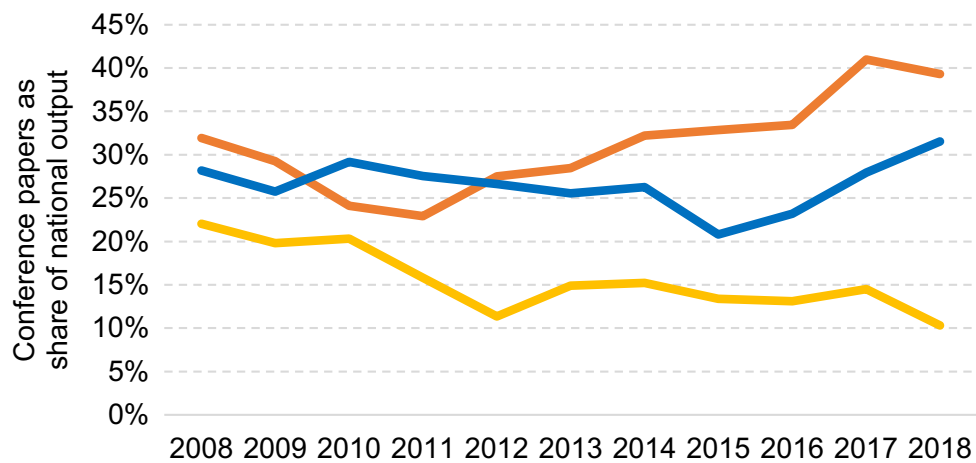

WoS Scopus Dimensions

ASEAN - document types

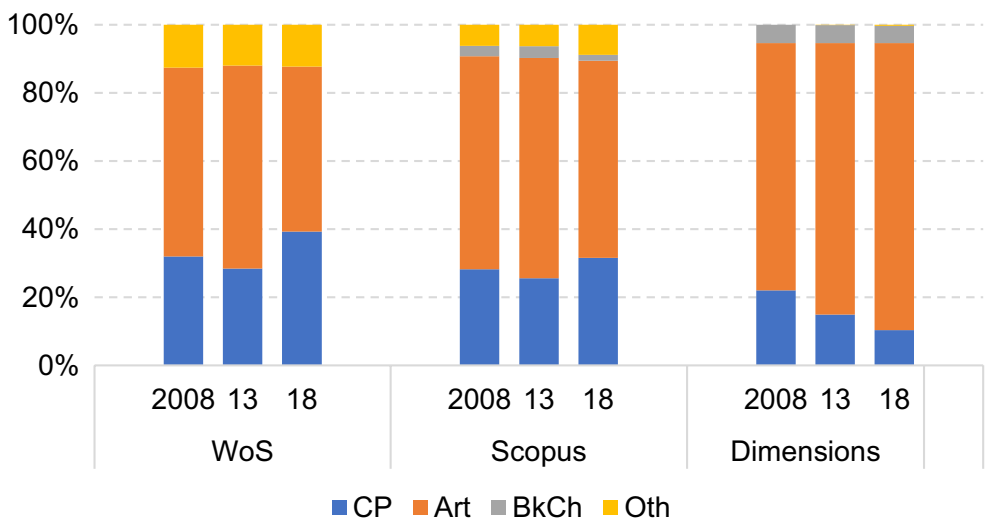

Fig. 3 Conference proceedings publishing trends-ASEAN 


\section{Brunei - conference papers}

120

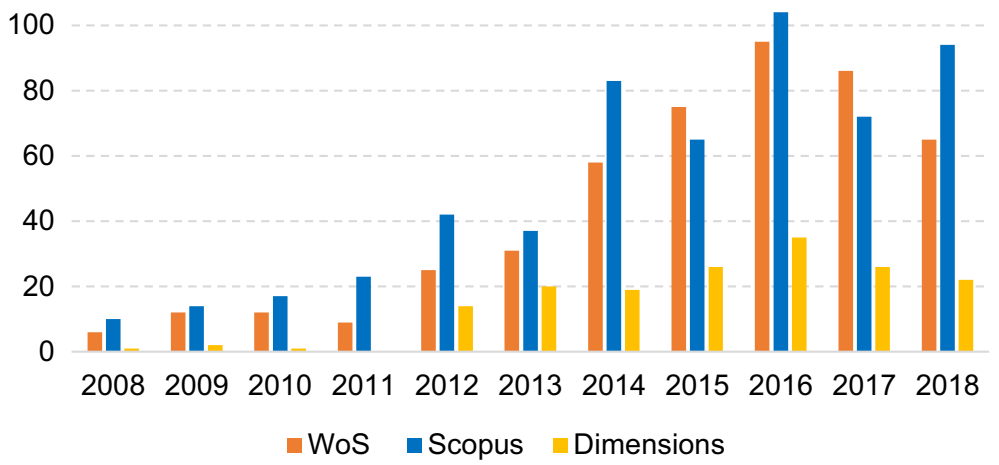

Brunei - conference papers share

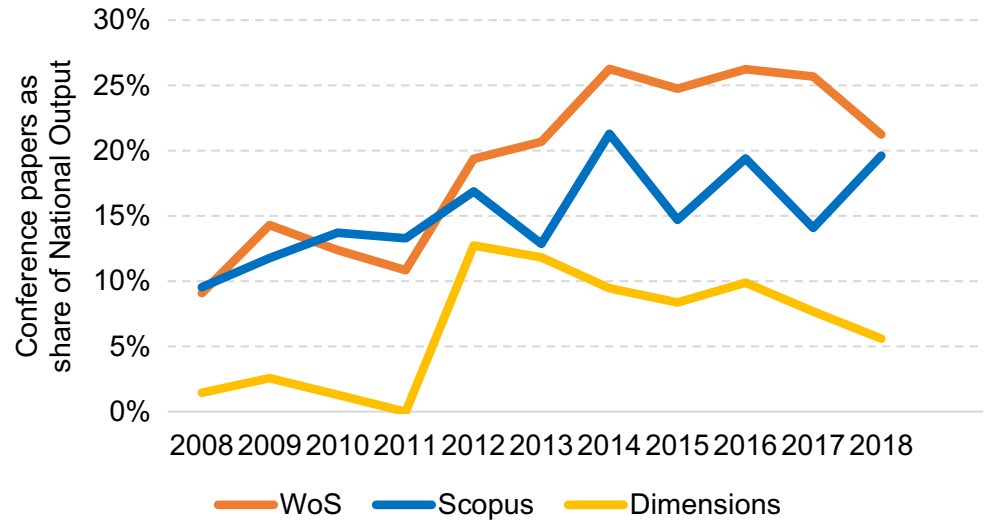

Brunei - document types

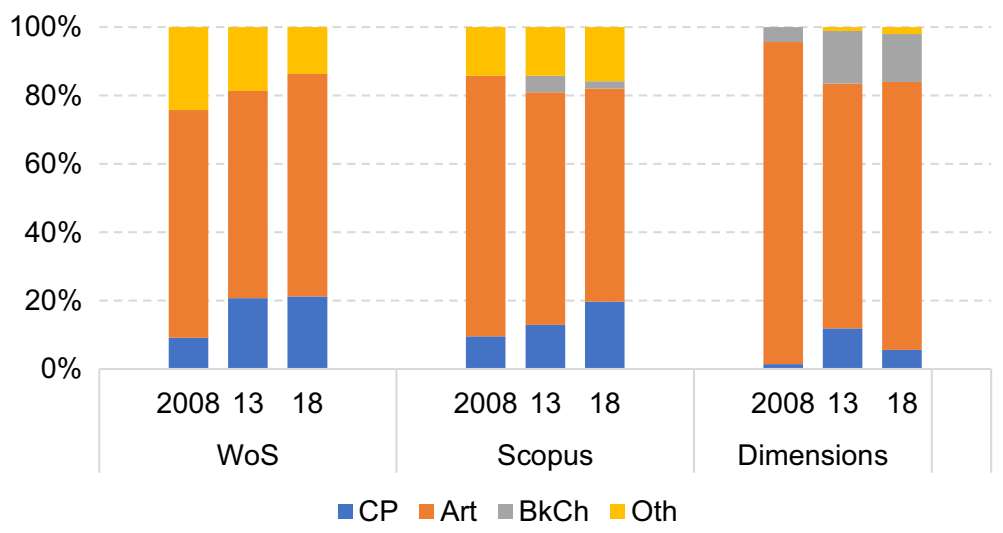

Fig. 4 Conference proceedings publishing trends-Brunei 


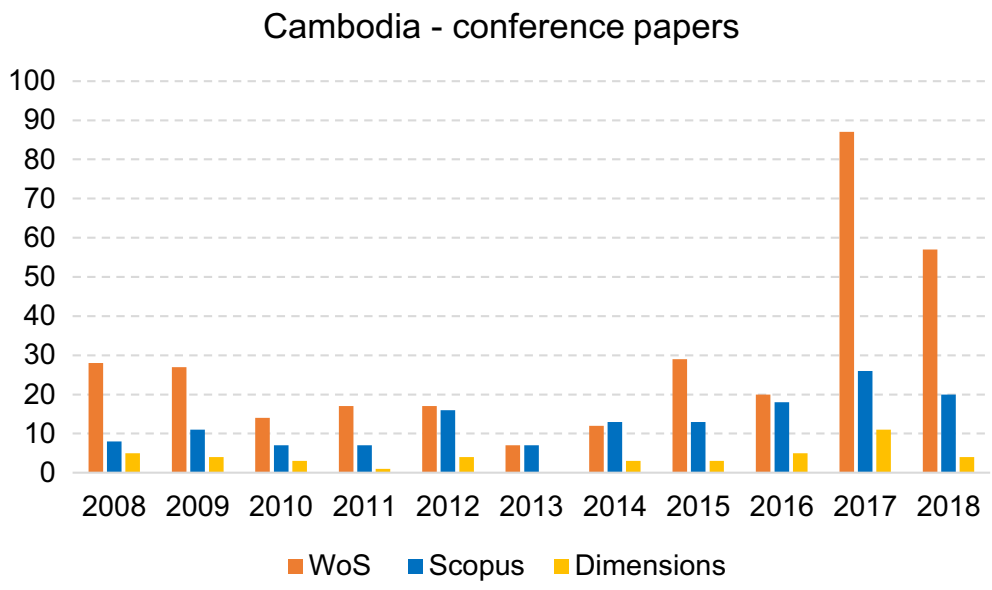

Cambodia - conference papers share

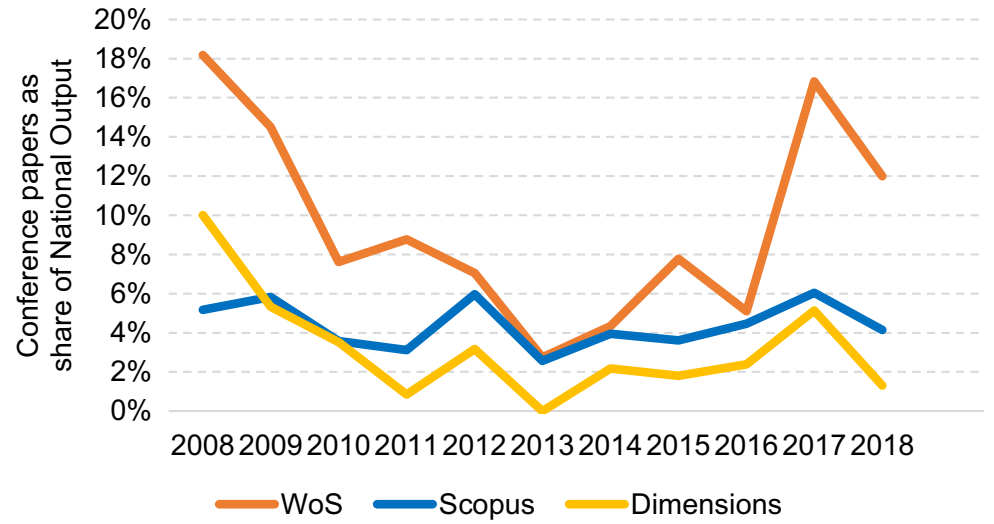

Cambodia - document types

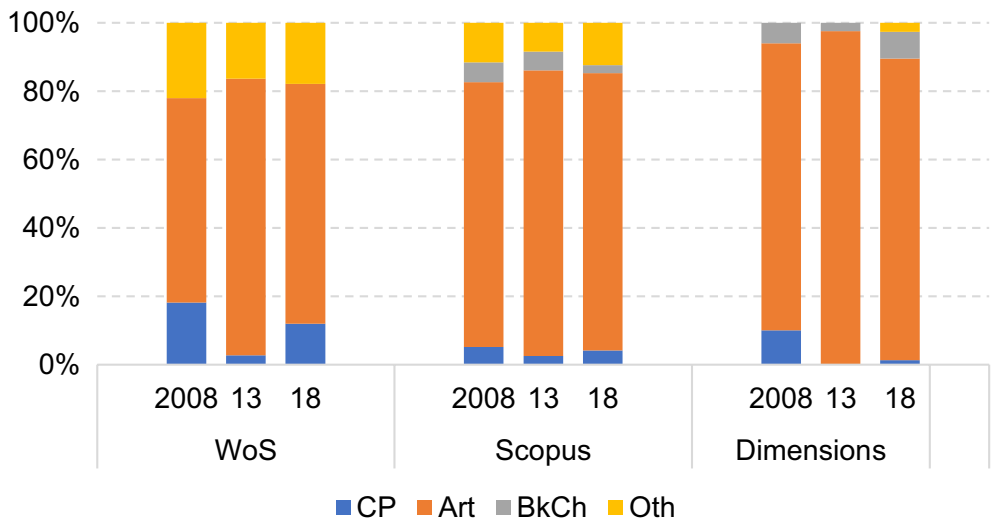

Fig. 5 Conference proceedings publishing trends-Cambodia 
Indonesia - conference papers

20,000
18,000
16,000
14,000
12,000
10,000
8,000
6,000
4,000
2,000

20082009201020112012201320142015201620172018

WoS $\backsim$ Scopus Dimensions

Indonesia - conference papers share

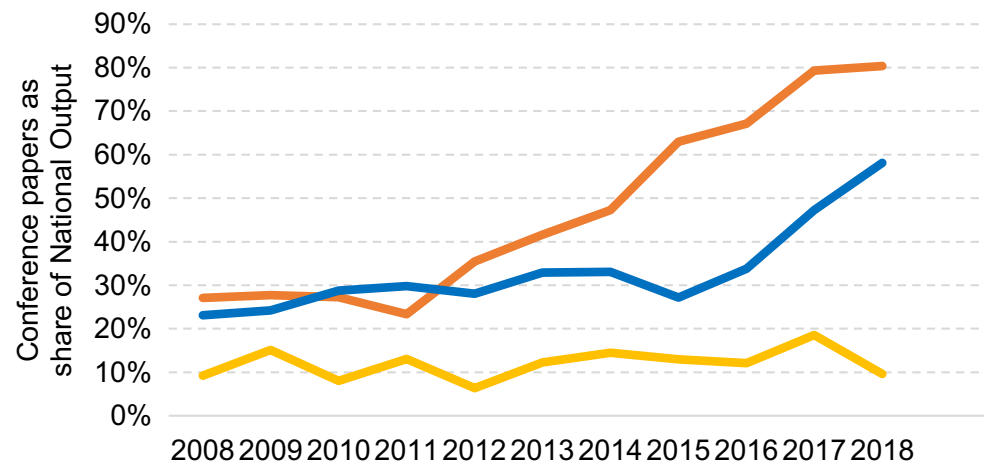

$\longrightarrow$ WoS $\longrightarrow$ Scopus Dimensions

Indonesia - document types

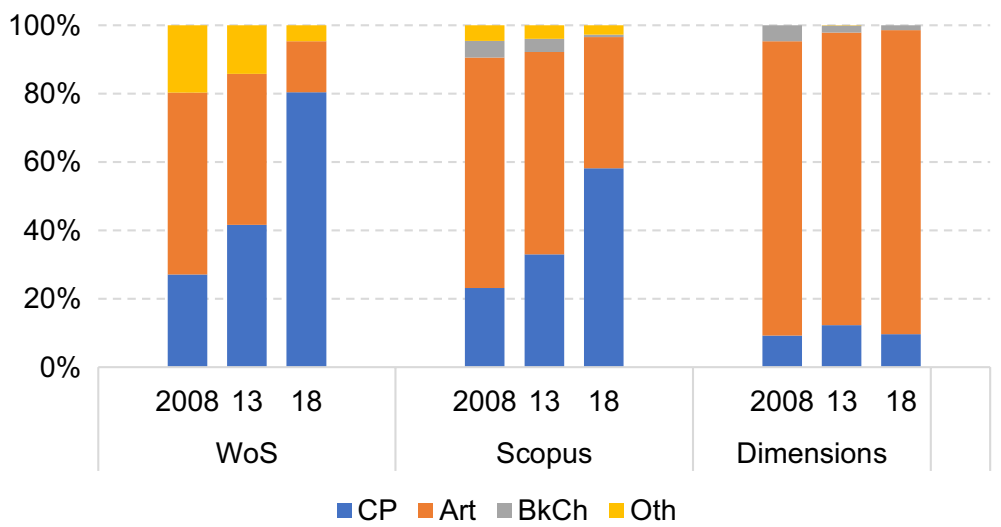

Fig. 6 Conference proceedings publishing trends-Indonesia 


\section{Laos - conference papers}

40

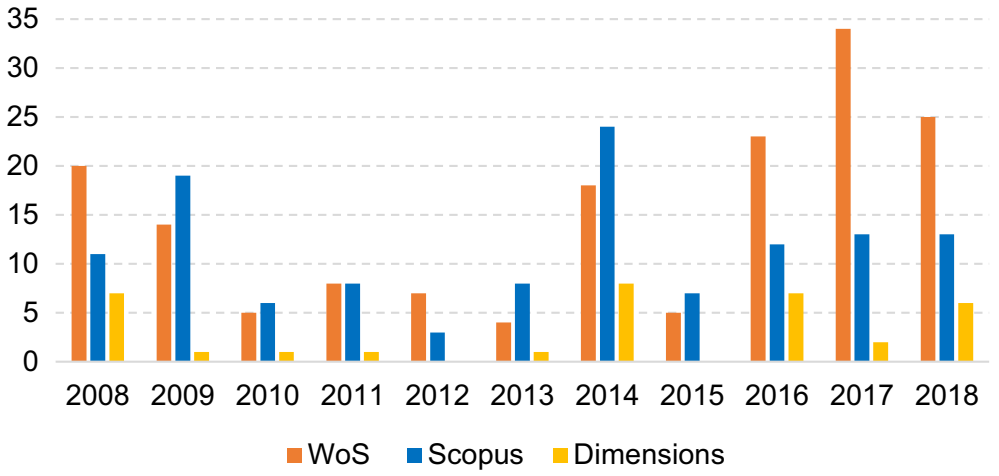

\section{Laos - conference papers share}

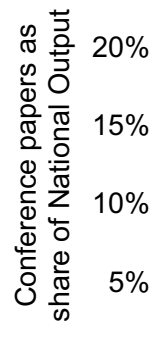

$0 \%$

20082009201020112012201320142015201620172018

WoS Scopus Dimensions

Laos - document types

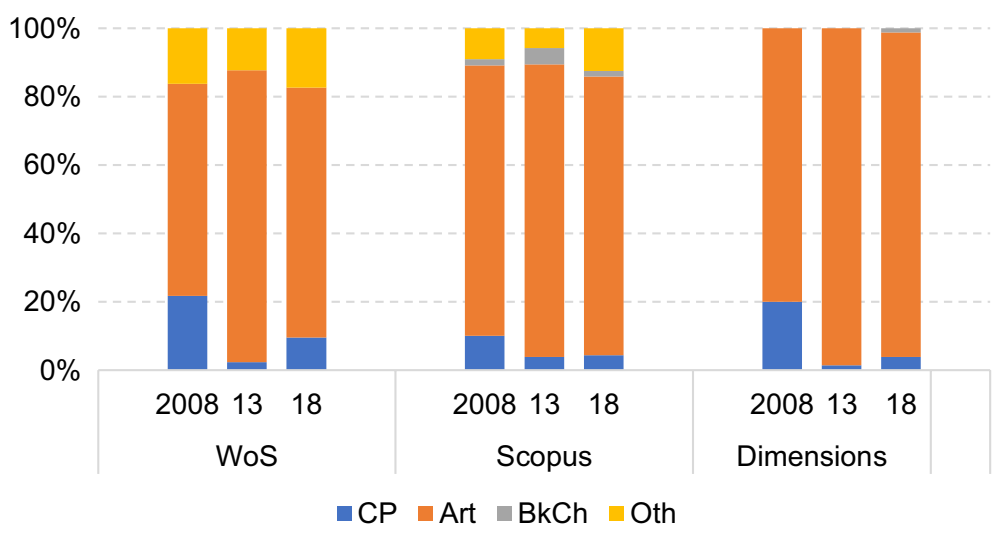

Fig. 7 Conference proceedings publishing trends-Laos 
Malaysia - conference papers

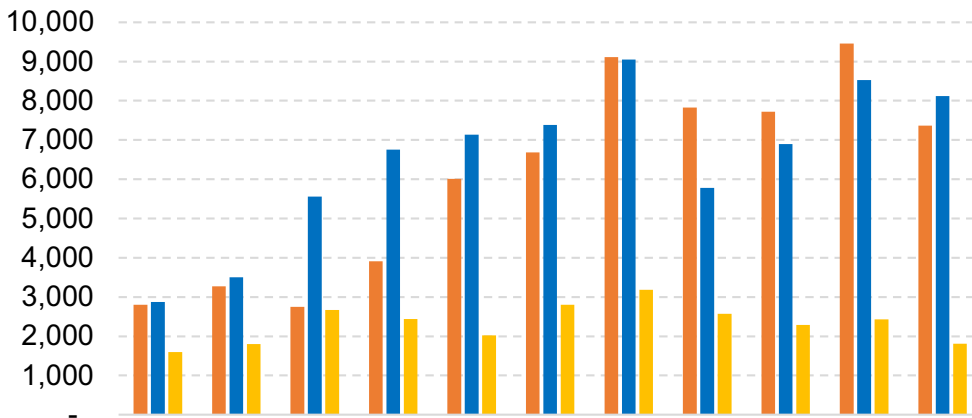

20082009201020112012201320142015201620172018

WoS $\quad$ Scopus $\quad$ Dimensions

Malaysia - conference papers share

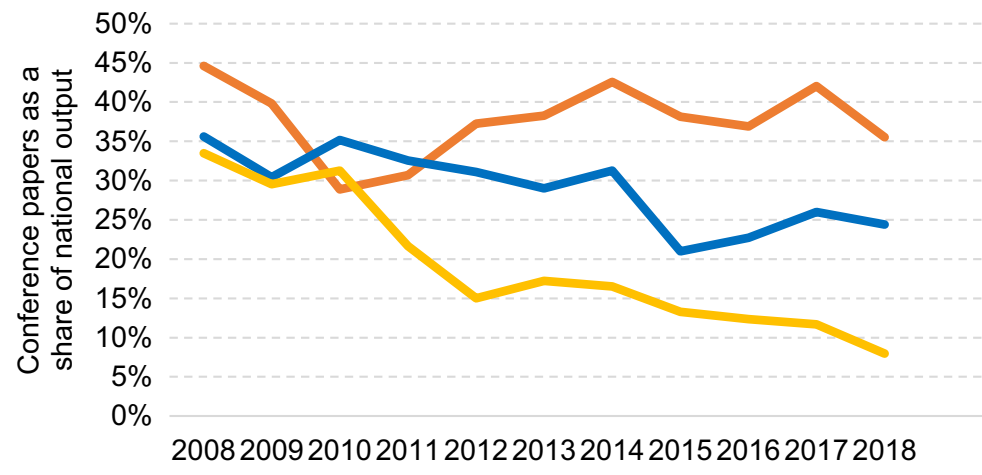

Wos $\longrightarrow$ Scopus Dimensions

Malaysia - document types

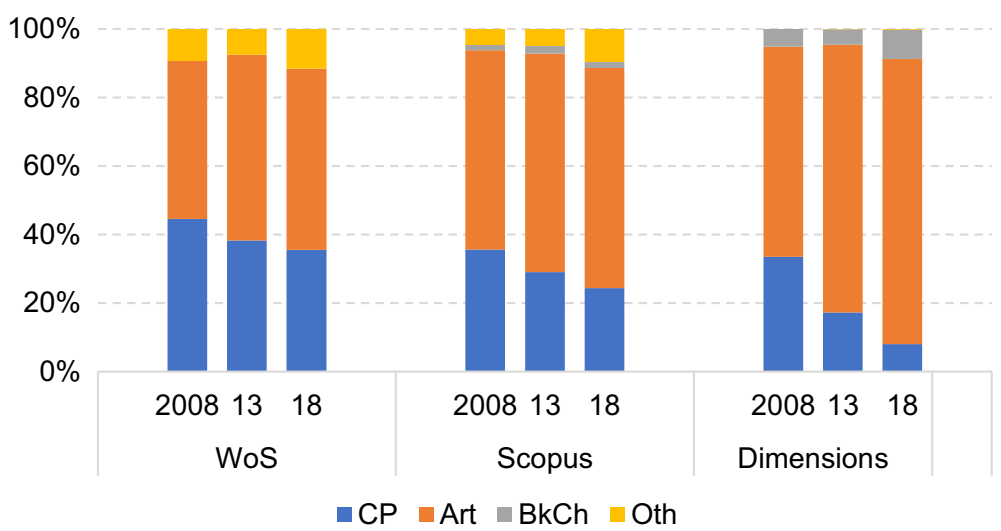

Fig. 8 Conference proceedings publishing trends-Malaysia 


\section{Myanmar - conference papers}

120

100

80

60

40

20

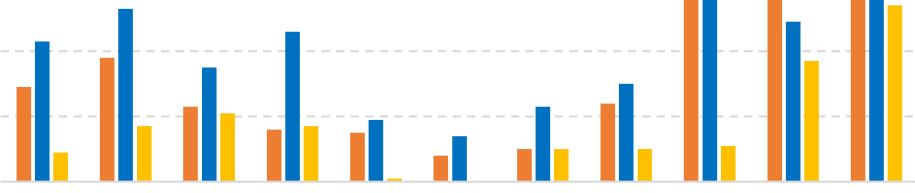

20082009201020112012201320142015201620172018

$\square$ WoS $\square$ Scopus $\square$ Dimensions

\section{Myanmar - conference papers share}

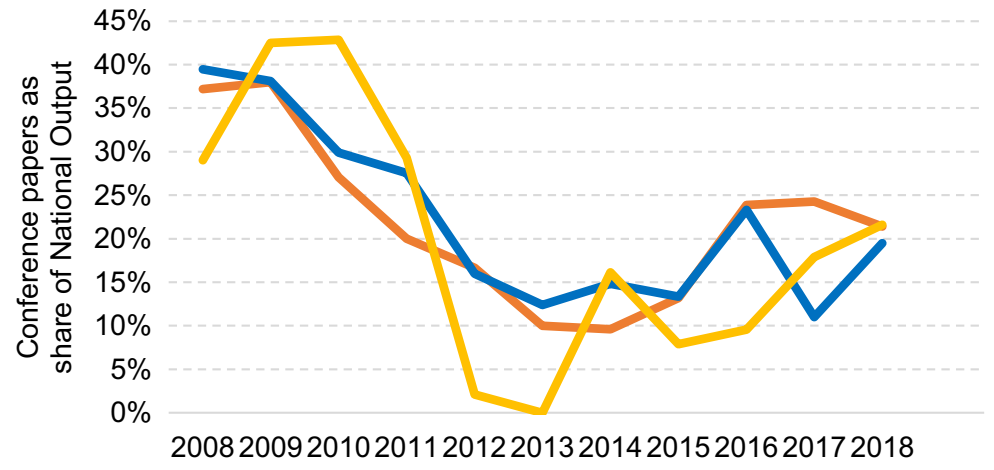

WoS Scopus Dimensions

Myanmar - document types

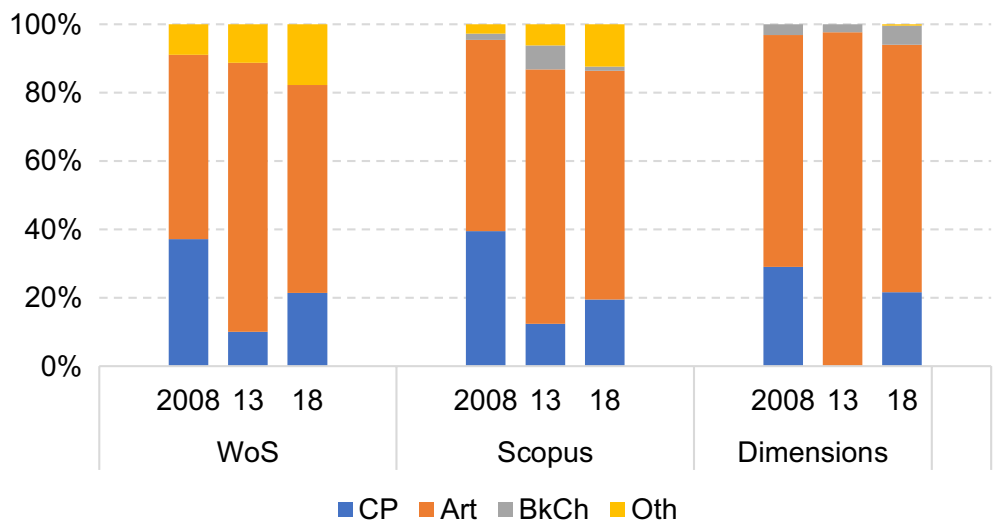

Fig. 9 Conference proceedings publishing trends-Myanmar 


\section{Philippines - conference papers}

1,200

1,000

800

600

400

200

$-$

20082009201020112012201320142015201620172018

$\square$ WoS $\backsim$ Scopus $\square$ Dimensions

Philippines - conference papers share

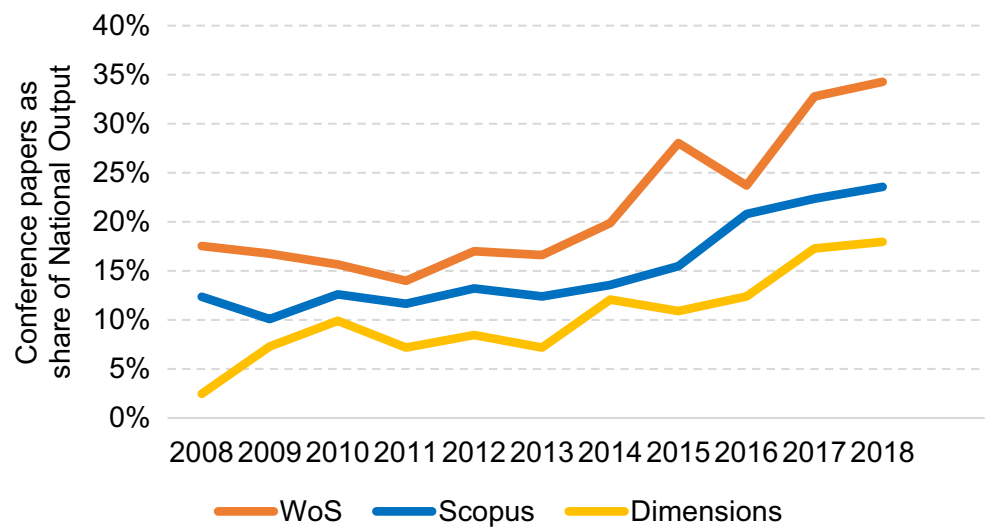

Philippines - document types

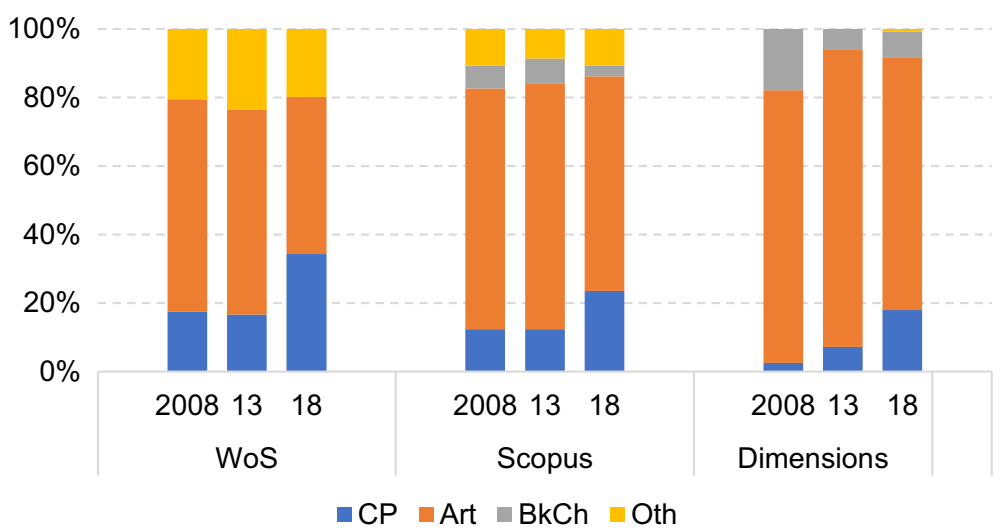

Fig. 10 Conference proceedings publishing trends-Philippines 


\section{Singapore - conference papers}

6,000

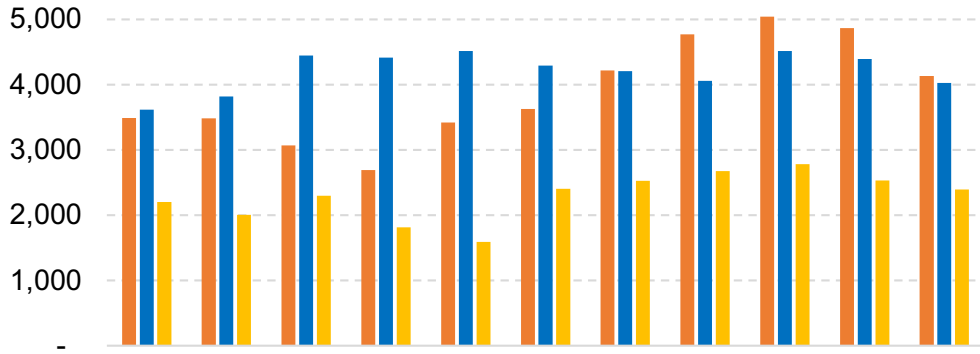

20082009201020112012201320142015201620172018

$\square$ WoS $\square$ Scopus $\square$ Dimensions

Singapore - conference papers share

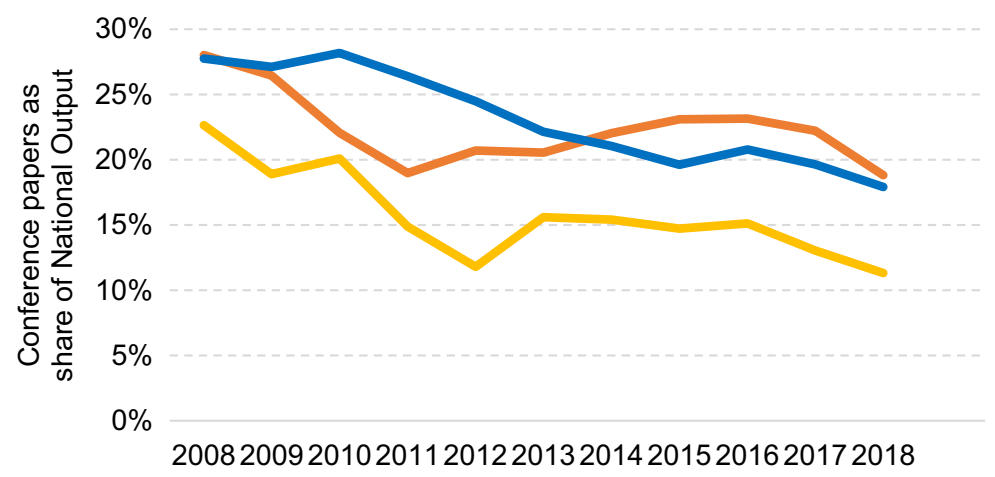

WoS Scopus Dimensions

\section{Singapore - document types}

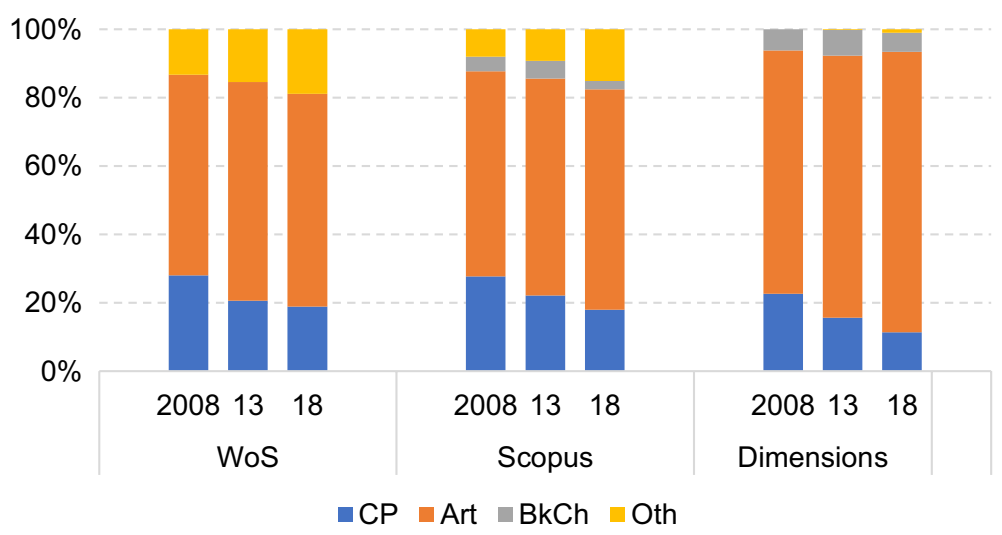

Fig. 11 Conference proceedings publishing trends-Singapore 
Thailand - conference papers

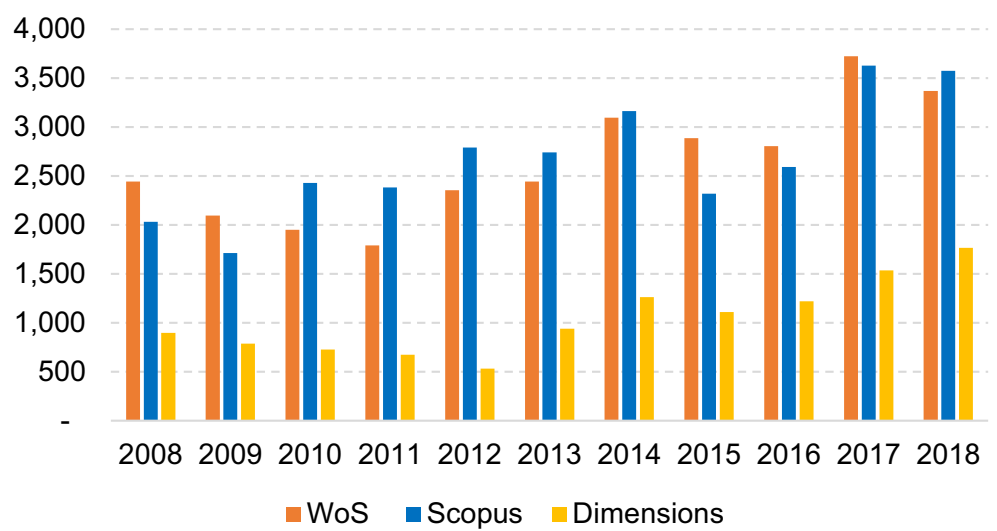

Thailand - conference papers share

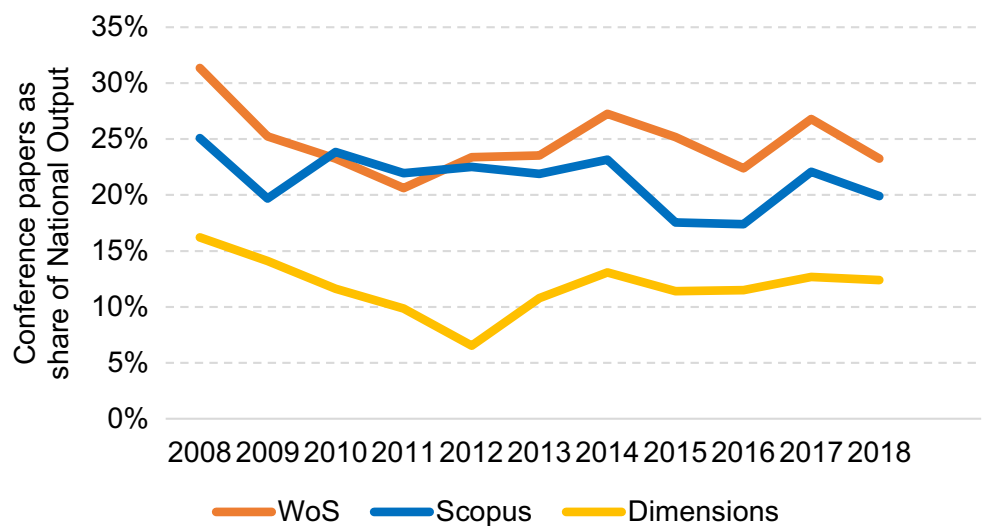

Thailand - document types

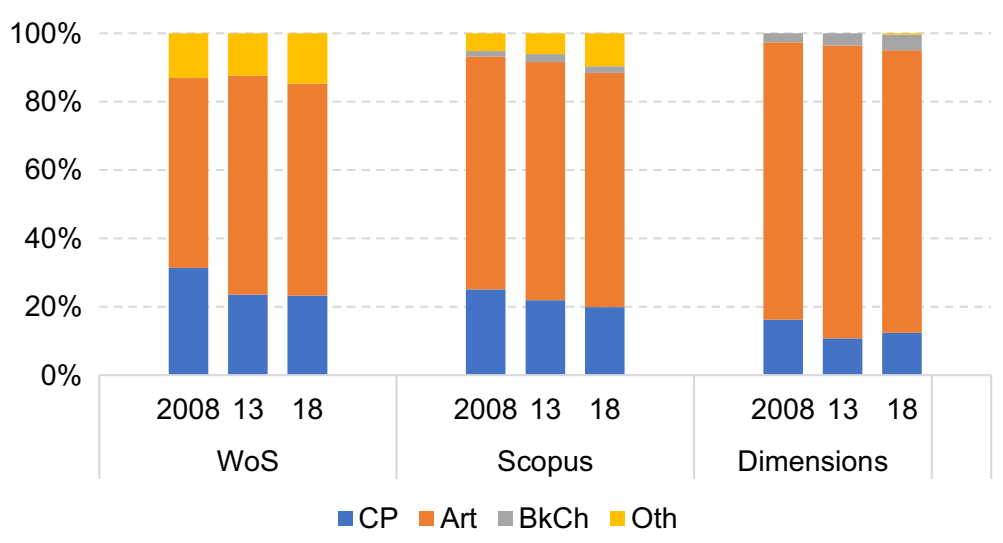

Fig. 12 Conference proceedings publishing trends-Thailand 


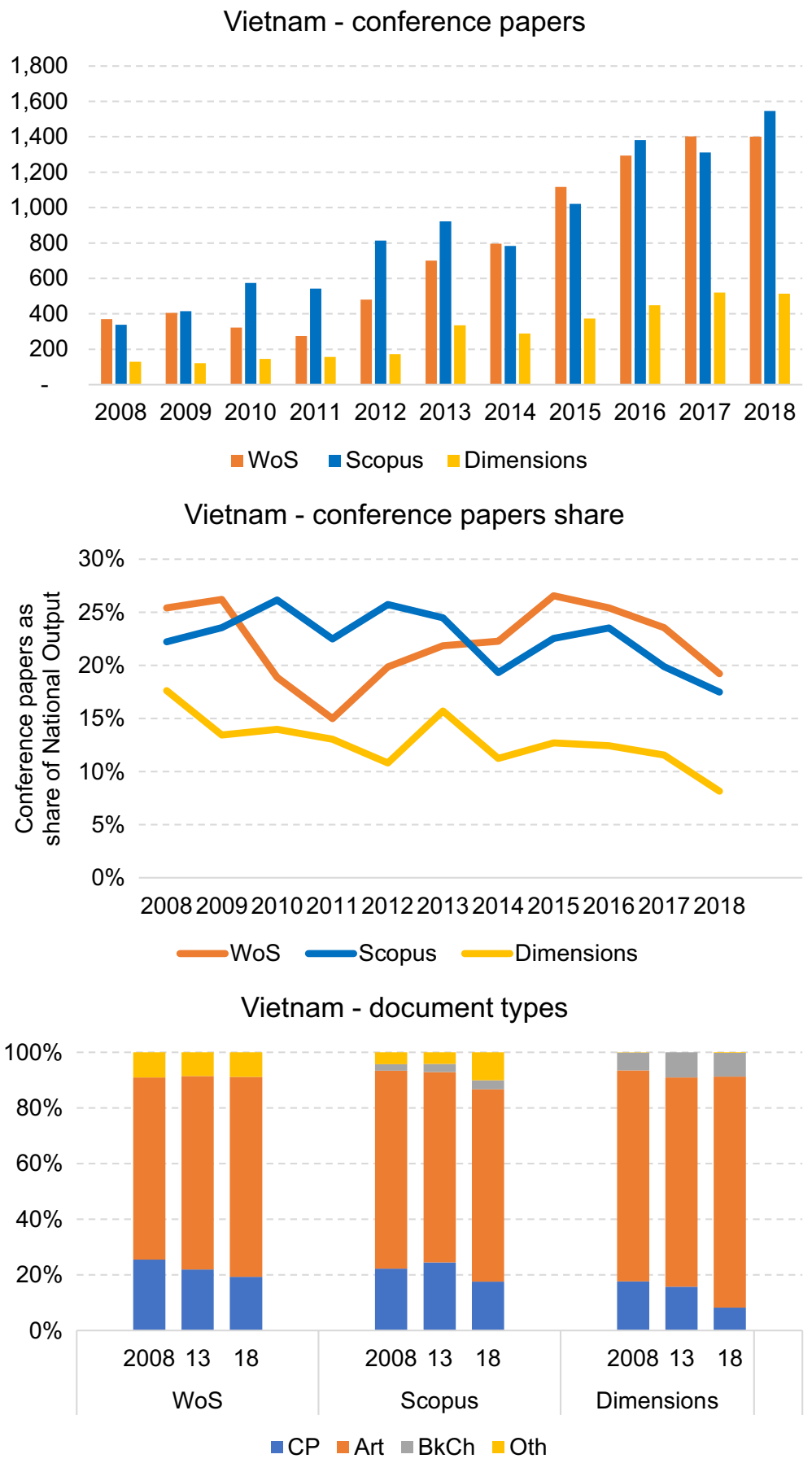

Fig. 13 Conference proceedings publishing trends-Vietnam 
by steady growth in the conference paper output that was in line with growth in publications of all document types and which therefore resulted in a relatively flat conference papers share graph. Malaysia did not fit the pattern perfectly because the conference share declined slightly in WoS and Scopus (Fig. 8) and significantly in Dimensions. The proportion of Malaysian conference papers was similar in all 3 databases at the beginning of the study period and diverged with a higher proportion of conference papers in WoS and a lower share in Dimensions. For Thailand and Vietnam (Figs. 12 and 13), the share of conference papers in Scopus tracked that of WoS and challenged WoS to varying degrees during two periods, the year 2005 and the years 2010-12, the period when there was a general reduction in conference proceedings indexing in WoS. The loss of conference paper share was taken up in each database mainly by journal articles.

The fourth group comprised countries with very low output of academic papers and more or less stable proportions of conference papers. The group included Brunei, Cambodia, Laos, and Myanmar (Figs. 4, 5, 7, 9). Although some differences could be observed for instance the trough in Myanmar's output between 2012-15, the low number of papers would be expected to exaggerate the significance of such observations.

\section{The case of Indonesia}

The most striking result was seen in the WoS data for Indonesia that showed a sharp inflection in the proportion of conference papers in national output starting after 2011. In the following 7 years, the share of conference papers rose from 23 to $80 \%$ of total annual output (Fig. 10). Indonesia's authors also increased their publication of other document types in the WoS, for instance journal article output has increased by $16.1 \%$ per year since 2008. However, this was far exceeded by the rate of conference papers that grew at $47.1 \%$ per year since 2008. The trend was less extreme but still marked in the Scopus database. Conference paper output from Indonesia increased more than six-fold in Scopus between 2008 and 2015 but remained within a range of 23\%-33\% of Indonesia's output in the overall database. In the following 3 years, the number of Scopus-indexed conference papers from Indonesia multiplied by more than 8 times, increasing faster than the journal article rate. By 2018 Indonesia's conference papers accounted for almost three-fifths (58\%) of the country's Scopus output. The trend in the Dimensions database did not appear to follow that of the WoS and Scopus. The number of conference proceedings written by Indonesian authors fluctuated in Dimensions until 2013 and accounted for between 7 and 16\% of national output. By the year 2017, the share had jumped to $18.6 \%$ accompanying a nearly four-fold increase in conference publications compared with 2015. However, the proportion fell back again in 2018, although this might have been affected by the rate at which conference papers were indexed in the database. The most recent years are less reliable, and the relative proportions might stabilise as 2018 data becomes more complete.

\section{Conference coverage expansion or organic growth?}

It is worth considering that Indonesia's increased conference representation in the WoS and Scopus might be due simply to the fact that these databases have added a number of conference series that contained large numbers of Indonesian papers prior to incorporation. In order to test this explanation, we looked at the 6 conference series with most Indonesian papers in the WoS and the corresponding 6 in Scopus in the last 5 years which was the period during which the major growth occurred. The aim was to 


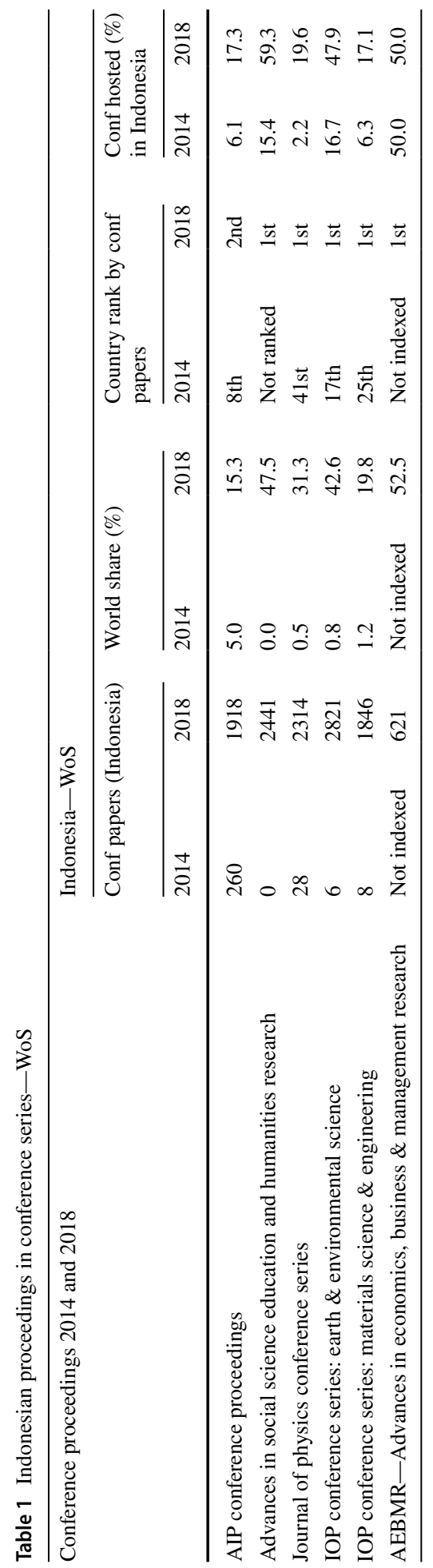


Table 2 Indonesian proceedings in conference series-Scopus

\begin{tabular}{|c|c|c|c|c|c|c|c|c|}
\hline \multirow[t]{3}{*}{ Conference proceedings 2014 and 2018} & \multicolumn{8}{|c|}{ Indonesia-Scopus } \\
\hline & \multicolumn{2}{|c|}{ Conf papers } & \multicolumn{2}{|c|}{$\begin{array}{l}\text { World share } \\
(\%)\end{array}$} & \multicolumn{2}{|c|}{$\begin{array}{l}\text { Country rank by } \\
\text { conf papers }\end{array}$} & \multicolumn{2}{|c|}{$\begin{array}{l}\text { Conf hosted } \\
(\%) \text { in } \\
\text { Indonesia }\end{array}$} \\
\hline & 2014 & 2018 & 2014 & 2018 & 2014 & 2018 & 2014 & 2018 \\
\hline AIP conference proceedings & 262 & 1924 & 6.1 & 15.0 & 7 th & 2nd & 6.1 & 17.3 \\
\hline Journal of physics conference series & 32 & 3778 & 0.6 & 26.2 & 39 th & 2nd & 2.2 & 19.6 \\
\hline $\begin{array}{l}\text { IOP conference series: earth \& environmen- } \\
\text { tal science }\end{array}$ & 9 & 3691 & 1.2 & 37.8 & 12 th & 2nd & 16.7 & 47.9 \\
\hline $\begin{array}{l}\text { IOP conference series: materials science \& } \\
\text { engineering }\end{array}$ & 10 & 2721 & 1.1 & 17.3 & 24 th & 2nd & 6.3 & 17.1 \\
\hline MATEC web of conferences & 0 & 1362 & 0.0 & 14.0 & Not ranked & $3 \mathrm{rd}$ & 0.0 & 13.8 \\
\hline Es3 web of conferences & 0 & 1.064 & 0.0 & 28.6 & Not ranked & 1 st & 0.0 & 18.8 \\
\hline
\end{tabular}

determine whether these series were recently added to the databases and if they contained large numbers of Indonesian papers prior to their indexation.

The top 6 conference series in terms of Indonesia authored papers are shown for the WoS (Table 1) and then for Scopus (Table 2). Four of the top conference series were the same in WoS and Scopus while each database included 2 unique series in their version of Indonesia's top 6. It was not possible to identify the specific conference series for Indonesian authors in the Dimensions database and therefore this section of the study used only the WoS and Scopus. Also shown is the percentage of that year's conference within the series that were physically hosted in a location in Indonesia.

The results from the WoS showed that in each of these series the number of Indonesian papers grew quickly in the 5 years from 2014 to 2018 (Table 1), more than sevenfold in the long-established AIP Conference series and more than 470-fold in the IOP Conference Series: Earth \& Environmental Science (Fig. 14). In most of the other series, there only a handful of Indonesian papers in 2014 but thousands in 2018. In the Advances in social science education and humanities research there were no Indonesian papers at all in 2014 and 2,441 in 2018. One could argue that many of these series were relatively new and have themselves grown from a very low base over the same time period of this study. That growth could be an explanation for the rapid growth in papers in these series from any country, not just Indonesia. However, the Indonesian contribution has grown a lot faster than the total as attested to by the increased proportion of papers from that country. In 2014 the proportion of published papers in these series from Indonesia ranged from 0 to $5 \%$ while by 2018 the range was $15.3 \%$ to $52.5 \%$. Only 2 of the 6 conference series studied were added to the WoS since 2014. In one of these (Advances in Social Sciences, Education \& Humanities Research), Indonesian papers were not present in the first year. In the other case (AEBMR-Advances in Economics, Business \& Management Research), Indonesian scientists authored fewer than $10 \%$ of the resulting proceedings papers in its first year.

The least remarkable growth was seen in the AIP Conference Proceedings in which Indonesia ranked 8th by number of conference papers in 2014 and rose to 2nd by 2018. In the other 5 series Indonesia published more conference papers than any other country in the world in 2018. This is a notable achievement when just 5 years earlier, the 


\section{AIP Conference Proceedings}

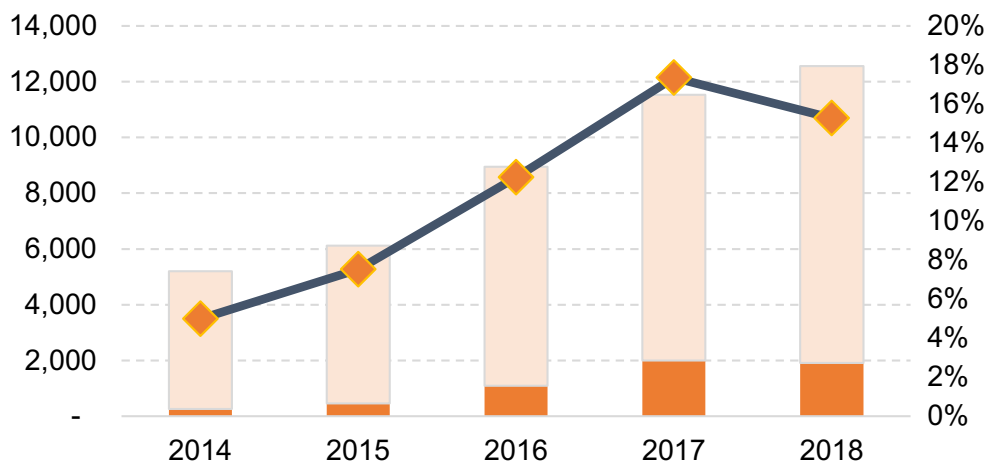

Indonesia Rest of world $\quad$-Indonesia's Share

\section{J Physics Conf Series}

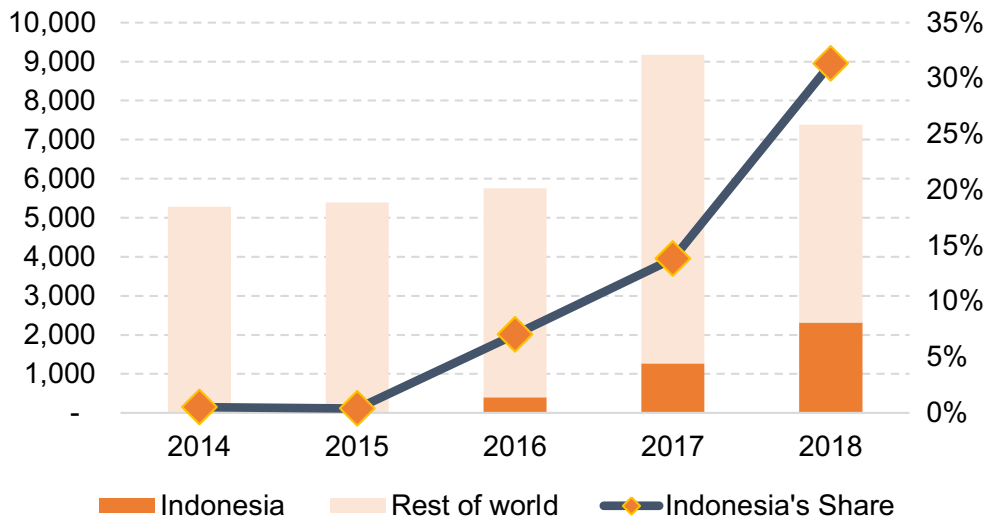

\section{Advances Soc Sci Ed \& Hum Res}

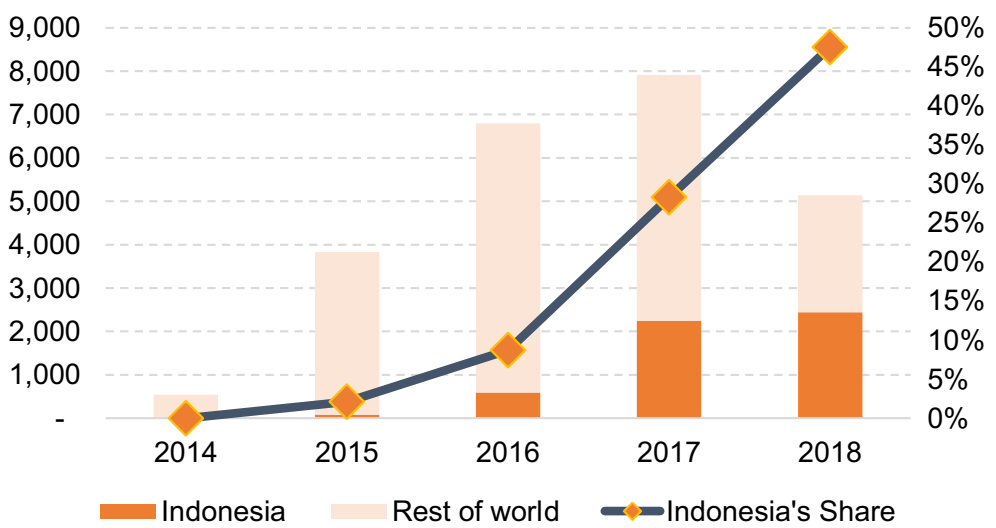

Fig. 14 Indonesian proceedings in conference series-WoS 


\section{IOP Conf Series - Earth \& Env Sci}

7,000

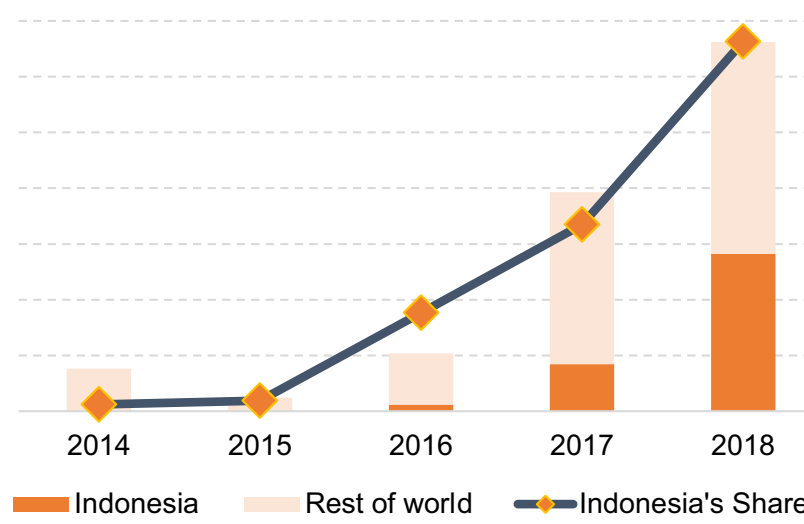

$45 \%$

$40 \%$

$35 \%$

$30 \%$

$25 \%$

$20 \%$

$15 \%$

$10 \%$

$5 \%$

$0 \%$

IOP Conf Series - Mat Sci Eng

10,000

9,000

8,000

7,000

6,000

5,000

4,000

3,000

2,000

1,000

-
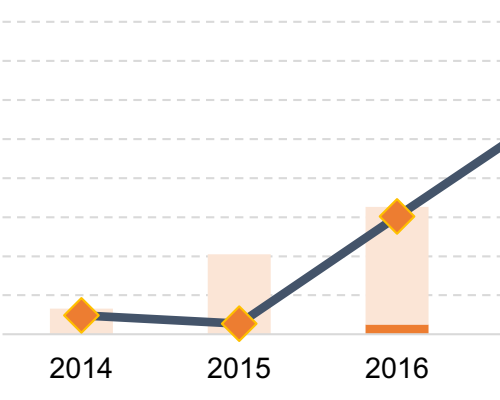

Indonesia

Rest of world $\quad-$ - Indonesia's Share

Advances Econ Bus Mgmt Res

2,500

$60 \%$

2,000

$-$

1,500

1,000

500

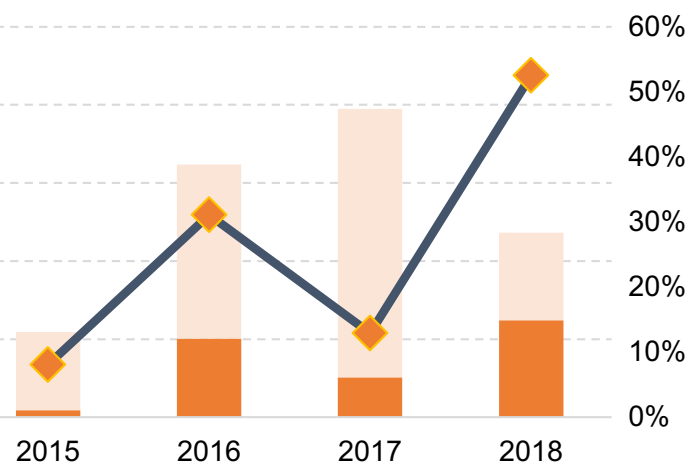

Indonesia

Rest of world

- - Indonesia's Share

Fig. 14 (continued) 
country ranked between 17 th and 41 st in the world and did not publish any papers at all in one of the series.

In Scopus the figures are no less impressive. In the 6 conference series in Scopus with most Indonesian papers, we see the same remarkable growth (Table 2). Four of those conference series were the same in WoS and Scopus although the number of papers indexed varies between databases. Two of the series shown in the WoS table are not indexed in Scopus while 2 that are in the Scopus table are not indexed in the WoS. In both the MATEC and the Es3 Web of Conference series, there were no Indonesian authored papers in 2014 but more than a thousand in 2018 (Fig. 15). In the Es3 Web of Conference that accounted for more than a quarter (28.6\%) of the world share of papers which was more than any other country in the world. In the MATEC Web of Conferences the Indonesian authored papers placed Indonesia as the third ranked country by output by 2018 .

\section{Conference hosting}

The data presented in Tables 1 and 2 show Indonesia's rank in the countries with most author affiliations on the proceedings papers in 6 conferences series by year. This means the publication year, and not necessarily the year the conference took place. The 2 columns furthest to the right show the proportion of conferences in the series that were hosted in Indonesia. The year the conference was hosted did not always coincide with the year in which the proceedings were published. Sometimes a conference is held at the end of 1 year, say in December and even a quick publisher will publish the conference proceedings in the following year. That means the publication numbers and conference hosting dates in Tables 1 and 2 are not infallibly related although we have made the assumption that in the majority of cases the relationship holds true. Even so, the data clearly shows an increase in the proportion of conference papers published by Indonesia based authors and an increase in the proportion of conferences hosted in Indonesia.

\section{Discussion}

\section{Conference proceedings indexing}

The steep increase in conference papers coincided with the launch of a CD Rom version of 'ISI Proceedings' in the early 2000s. The database owner, then Thomson Reuters, sought to create more value in this product by adding proceedings papers from conferences held in the preceding 5 years ${ }^{1}$ in addition to those that were indexed annually. The additional conferences swelled the number of proceedings papers that resulted in a peak of $25 \%$ in the proportion of conference papers in the WoS in 2003. Growth tempered after 2009 as emphasis (and resources) shifted towards the indexing of books and book chapters in preparation for the launch of the Book Citation index in 2011. Once the Book Citation Index was launched, evaluation and indexing work resumed its usual pace on proceedings. In the most recent five years, the conference papers have reached a stable ratio of around 1:4 compared with journal papers as both grew at a similar rate.

1 The author is a former employee of Thomson Reuters. 
AIP Conference Proceedings

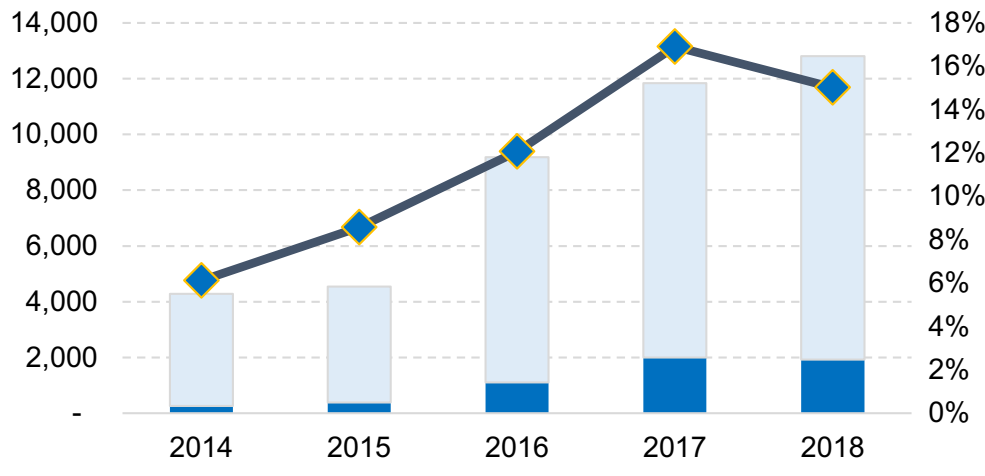

Indonesia $\square$ Rest of world $\quad-$ Indonesia's Share

J Physics Conf Series

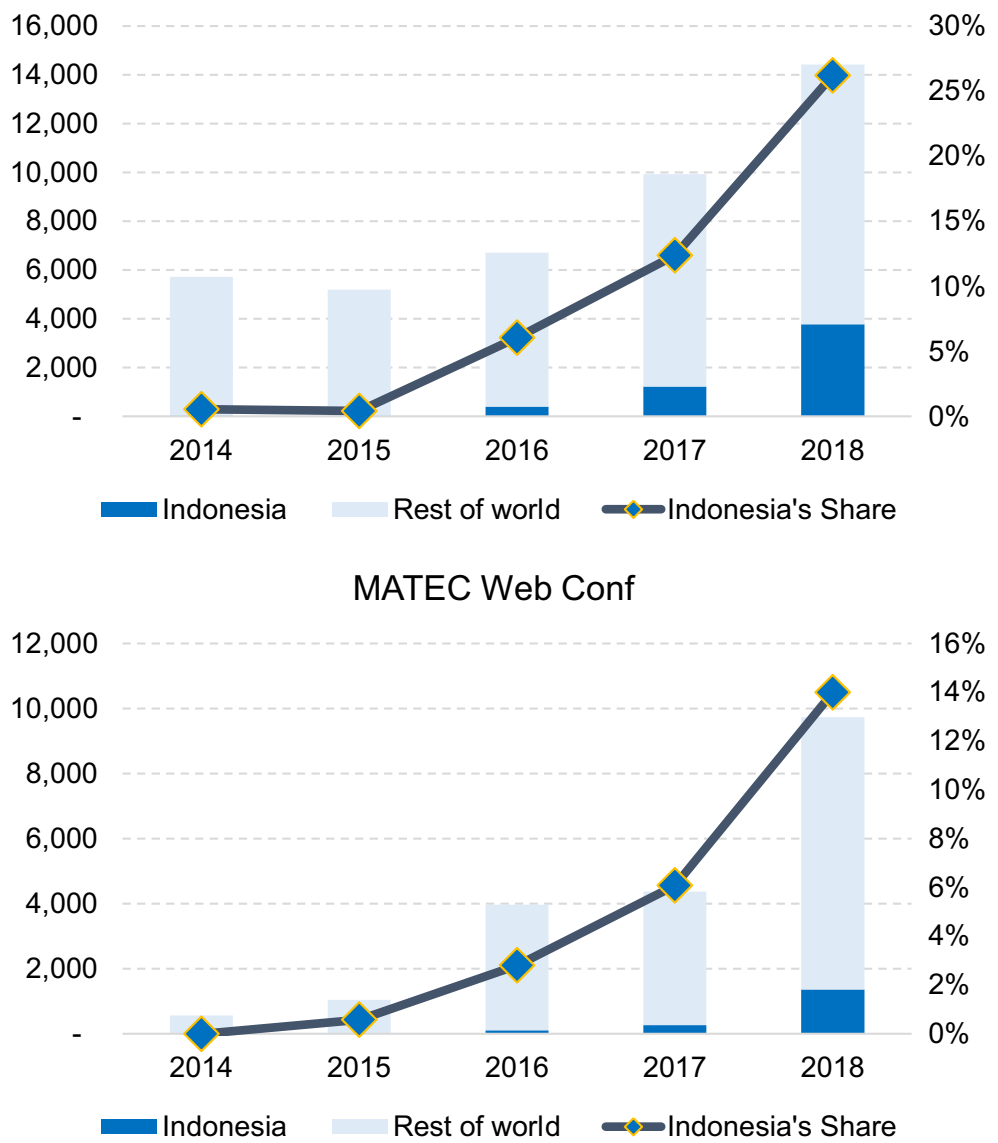

Fig. 15 Indonesian proceedings in conference series-Scopus 


\section{IOP Conf Series - Earth \& Env Sci}

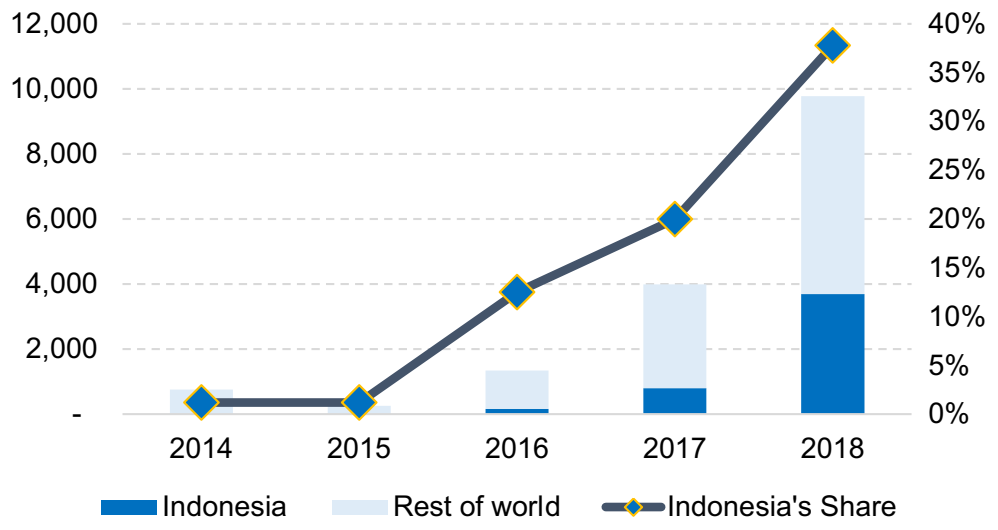

\section{IOP Conf Series - Mat Sci Eng}

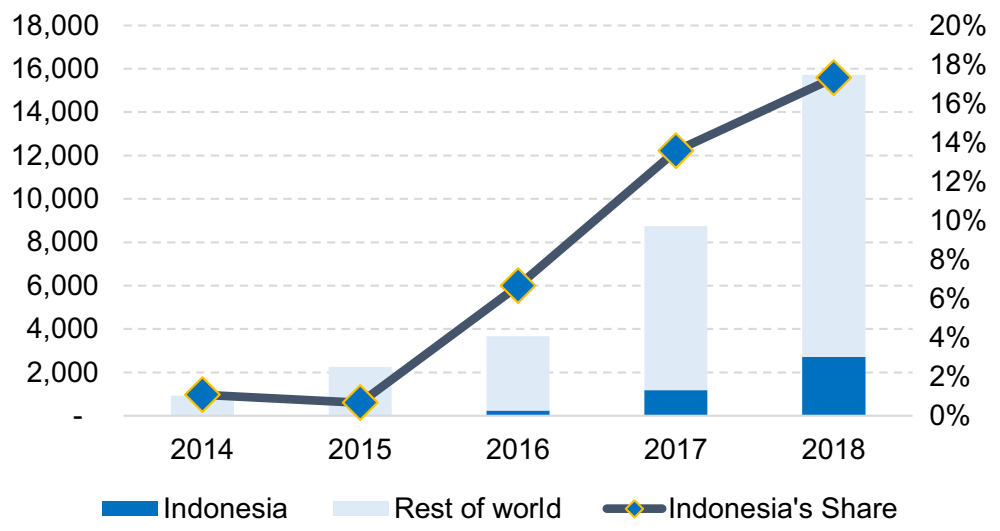

\section{Es3 Web Conf}

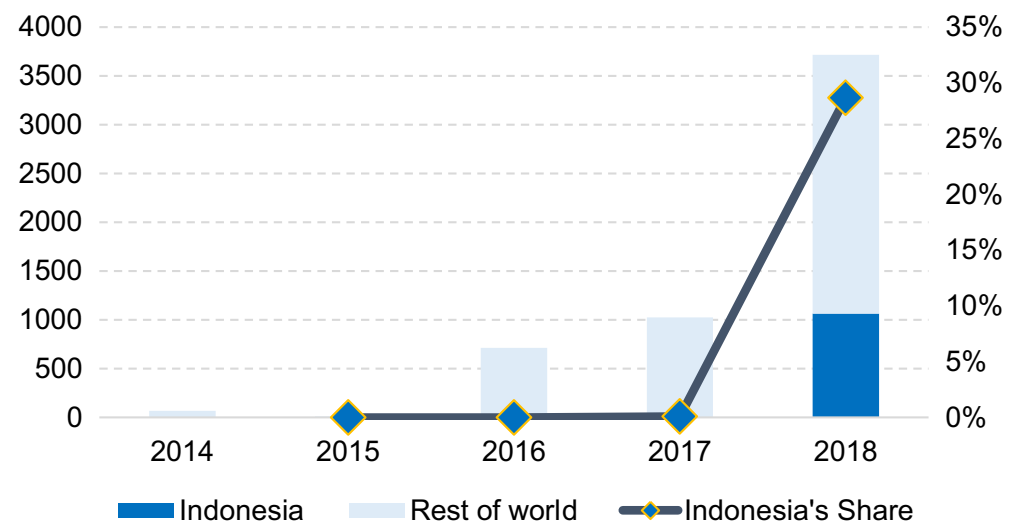

Fig. 15 (continued) 
In the Scopus database, the share of conference papers showed a similar pattern to that seen in the WoS (Fig. 2) albeit less extreme and shifted approximately four years later. The relative delay of the phenomenon is possibly due to the later addition of conference papers to Scopus as part of the Scopus Conference Expansion Programme (Elsevier 2015) in which over 400,000 conference papers were added to the database during the years 2011-2014. This was several years after the CPCI was added to the WoS and would explain the time difference between the 2 databases in the surge of conference papers.

The reason for the lower proportion of conference papers in Dimensions is likely due to greater coverage of journal articles globally combined with a smaller coverage of conference proceedings papers. It may also be due to the differences in document type classification, namely that all journal material is classified as article in Dimensions while articles in the other 2 databases are sub-sets of journal material which also contains other document types including conference proceedings. Journal publishers are possibly more diligent than conference organisers in generating and depositing DOIs in the Crossref database which is the backbone of the Dimensions database. That would partially explain more journal content being indexed in Dimensions than conference proceedings publications. The owners of WoS and Scopus, however, have each made concerted campaigns to boost the representation of conference material which were followed by sustained increased share thereafter.

\section{ASEAN region}

The clustering exercise revealed sub-regional trends with the ASEAN countries. By far the most interesting country for further study was Indonesia. Its steep and sustained increase in conference publishing (Fig. 10) deviated so much from the global pattern that we investigated 2 potential explanations. The first was whether non-indexed conference series containing large numbers of Indonesian conference papers had suddenly been indexed by the databases used in the study. The author considers this unlikely, because the indexing policies did not change significantly during this period and because the analysis showed the conferences with the largest increase of papers from Indonesia were already indexed. The second was whether hosting conferences in Indonesia had a positive impact on output. The only 2 other countries to depart from the global norm were the Philippines whose share of conference papers also increased, and Singapore whose share declined. In both of these cases, the results were notable but did not show enough difference from the global picture to warrant further investigation. Slight differences from the global average by any individual country are to be expected, and those observed from the Philippines and Singapore were most likely examples of this deviance rather than any major shift in publishing behaviour.

The differences shown in Indonesia's conference publishing pattern between the 3 databases might be explained by the unique coverage policy of each database and the precise timing of when large conference series were added to the databases. However, there is a clear preferential increase in Indonesian conference paper output in WoS and Scopus that implicates changing publishing behaviour in Indonesia. This suggests that the most likely explanation for the observed increase in conference paper output from Indonesia can be found within the Indonesian academic community.

Increased visibility of conference papers in global databases means research managers and administrators are now able to evaluate conference proceedings papers among other indicators of an individual's productivity. This raises the possibility that academics have chosen to preferentially publish conference proceedings rather than journal articles or book 
chapters. If one simply counts all output found in a citation index linked to an academic, then one will be rewarding all indexed document types equally. This might become an incentivising factor in publishing one type of paper over another in countries where academic promotion policy does not distinguish between document types. Indeed, conversations with Indonesian academics and one Indonesian conference organiser supported this hypothesis. The organiser sent ministry guidelines for academic recruitment and promotion issued in 2012, 2014, and 2017. To his knowledge, there were "no rules regarding publications in the 2000s. This policy of spurring the number of publications in Indonesia was only implemented 3-5 years ago." He went on to say Indonesians were incentivised by Scopus publications which were more easily and quickly attained through conference proceeding and that "the goal was catching up with Malaysia and Singapore in Scopus output."

An alternative possibility is that increased database coverage is responsible for greater visibility of Indonesian publication activity. Most of the conference series studied were already indexed in the citation databases before any significant contribution from Indonesia, thereby dismissing the sudden addition of specific conferences to the databases as a plausible explanation for the growth. The only exception was AEBMR-Advances in Economics, Business \& Management Research which was added to the WoS in 2015. In that year, 44 Indonesian papers were added, and that figure rose by more than 14-fold to 621 in the following 4 years. The results showed that Indonesian authors have indeed greatly increased their conference proceedings publication output within the last 5 years and the presence of these papers in the databases was not explained by sudden indexing decisions. In personal communication, a leading conference publisher supported the hypothesis that some authors from Indonesia are choosing the conference route as quicker than the journal article alternative and found it easier to pass peer review on conference papers than journal articles.

In almost all the conference series studied, there was an increasing proportion of the conferences hosted in Indonesia. The growing interest of the Indonesian academic community in attending conferences and publishing conference papers may well have stimulated the increased number of conferences organised and hosted in Indonesia. The conference publisher mentioned earlier also suggested that investment by Indonesia in supporting science conferences has led to the increasing number of events physically hosted in Indonesia. The combination of government investment in science, ministry guidelines incentivising publishing, and academics' preference for conference proceedings are the likely cause of the increased number of locally hosted conferences.

\section{Conclusions}

Both the WoS and Scopus have made concerted efforts at different times to add conference proceedings papers to their databases and these remain an important part of both databases. The addition of the Conference Proceedings Citation Index to the WoS caused a major jump in representation of conference material in the database. Similarly, the Scopus Expansion Project added a lot of conference proceedings to the Scopus database although this occurred several years later and consequently the conference proceedings remain more prominent in the WoS than Scopus. Dimensions indexes more journal articles and fewer conference proceedings papers than the WoS and Scopus and therefore appears to hold a lower proportion of conference proceedings. However, conference 
proceedings are often classified as journal articles in Dimensions which both raises the number of articles and reduces the number of proceedings papers. The backbone of the Dimensions content is Crossref and its content is therefore determined by those publishers that have deposited DOIs in the Crossref database. Journal publishers are likely to be more diligent about this process than conference organisers because DOIs are decisive when journals are evaluated for inclusion in many prestigious databases. These practices contribute to the apparently lower proportion of conference papers in Dimensions than the other two databases.

Studying the dynamics of conference proceedings publishing depends on multiple factors that affect different parts of the world to varying degrees, and these stories may be obscured when we look at the global average figures. Consequently, the second part of the paper was a case study of the ASEAN region as a well-defined group of 10 component countries to identify any interesting trends. Conference proceedings output started from a low base in the ASEAN countries and on average saw a recent increase in conference proceedings publishing in the WoS and Scopus while the proportion of journal articles and book chapters and other document types declined. The 10 countries were organised into 4 clusters with only Indonesia and the Philippines showing sustained increase in conference publishing, while Singapore declined. The other countries generally followed the global trend. Indonesia was by far the most interesting case due to the extent of the apparent wholesale shift of its country's authors towards publishing conference proceedings at the expense of other document types. Publishing of journal articles also increased but were easily outpaced by the conference papers which accounted for the majority of change in the ASEAN region's publishing pattern.

Further investigation into potential explanations for the disproportionate increase in conference proceedings publications from Indonesian academics examined the database coverage of Indonesian conference papers and the changing dynamics within the academic community. Expansion of conference proceedings coverage in both the WoS and Scopus has been shown to be partially responsible for the increased number of research papers from Russian scientists (Moed, Markusova and Akoev 2018). The findings showed the phenomenon reflected real growth in published conference papers by Indonesian authors rather than being the result of increased database coverage. They also determined that Indonesia has rapidly and recently increased its hosting of international conferences whose proceedings are indexed in the major citation indexes. The increase in conference hosting is a plausible explanation for the corresponding growth in Indonesian conference publications, as it must be easier to attend and present a paper at home than abroad where international travel might be a barrier. Further research would be required to determine whether the locally hosted conferences bred increased output, or if improved Indonesian research had attracted international conferences to the country.

The local publishing guidelines and sometimes controversial credit-based assessment system (Singh Chawla 2018) might have provided the conditions and stimulus for Indonesian academics to increase their publication output and advance their careers partially through a preference for publishing conference papers and those same policies could have also incentivized scientists to host international conferences in Indonesia. A recent study found an isolated case of preferential conference proceedings publishing in Europe and attributed that to the national policy for evaluating academics (Vanecek and Pecha 2020). Follow up studies are therefore encouraged to look at the Indonesian local higher education and research promotional policies, and surveys of Indonesian scientists would be especially warranted. 
Acknowledgements Ton van Raan and Ludo Waltman for inspiring me to embarque upon this journey and guiding me expertly through it. Roy Hendroko Setyobudi for advice on the Indonesian higher education system and conferencing. Kim Eggleton for advice on conference publishing trends.

\section{Funding None.}

\section{Compliance with ethical standards}

Conflict of interest The author declares that they have no conflict of interest.

Open Access This article is licensed under a Creative Commons Attribution 4.0 International License, which permits use, sharing, adaptation, distribution and reproduction in any medium or format, as long as you give appropriate credit to the original author(s) and the source, provide a link to the Creative Commons licence, and indicate if changes were made. The images or other third party material in this article are included in the article's Creative Commons licence, unless indicated otherwise in a credit line to the material. If material is not included in the article's Creative Commons licence and your intended use is not permitted by statutory regulation or exceeds the permitted use, you will need to obtain permission directly from the copyright holder. To view a copy of this licence, visit http://creativecommons.org/licenses/by/4.0/.

\section{References}

Abramo, G., \& D'Angelo, C. A. (2014). How do you define and measure research productivity? Scientometrics, 101(2), 1129-1144. https://doi.org/10.1007/s11192-014-1269-8

Archambault, E., Campbell, D., Gingras, Y., \& Lariviere, V. (2009). Comparing of science bibliometric statistics obtained from the web and scopus. Journal of the American Society for Information Science and Technology, 60(7), 1320-1326. https://doi.org/10.1002/asi.21062

ASEAN. (2019). Association of Southeast Asian Nations Website.

Bar-Ilan, J. (2010). Web of science with the conference proceedings citation indexes: The case of computer science. Scientometrics, 83(3), 809-824. https://doi.org/10.1007/s11192-009-0145-4

Chen, D., \& Dahlman, C. (2005). The Knowledge Economy, the KAM Methodology and World Bank Operations. Retrieved from https://documents.worldbank.org/curated/en/695211468153873436/The-knowl edge-economy-the-KAM-methodology-and-World-Bank-operations

Drott, M. C. (1995). Reexamining the role of conference papers in scholarly communication. Journal of the American Society for Information Science, 46(4), 299-305. https://doi.org/10.1002/(SICI)10974571(199505)46:4\%3c299::AID-ASI6\%3e3.0.CO;2-0

Elsevier. (2015). Scopus conference expansion programme.

Garvey, W. D., Lin, N., Nelson, C. E., \& Tomita, K. (1972a). Research studies in patterns of scientific communication: I. General description of research program. Information Storage and Retrieval, 8(3), 111122. https://doi.org/10.1016/0020-0271(72)90040-X

Garvey, W. D., Lin, N., Nelson, C. E., \& Tomita, K. (1972b). Research studies in patterns of scientific communication: II. The role of the national meeting in scientific and technical communication. Information Storage and Retrieval, 8(4), 159-169. https://doi.org/10.1016/0020-0271(72)90001-0

Glänzel, W., Schlemmer, B., Schubert, A., \& Thijs, B. (2006). Proceedings literature as additional data source for bibliometric analysis. Scientometrics, 68(3), 457-473. https://doi.org/10.1007/s1119 2-006-0124-y

González-Albo, B., \& Bordons, M. (2011). Articles vs. proceedings papers: Do they differ in research relevance and impact? A case study in the library and information science field. Journal of Informetrics, 5(3), 369-381. https://doi.org/10.1016/j.joi.2011.01.011

Goodrum, A. A., McCain, K. W., Lawrence, S., \& Giles, C. L. (2001). Scholarly publishing in the internet age: A citation analysis of computer science literature. Information Processing and Management, 37(5), 661-675. https://doi.org/10.1016/S0306-4573(00)00047-9

Harzing, A.-W. (2019). Two new kids on the block: How do crossref and dimensions compare with google scholar, microsoft academic, scopus and the web of science? Scientometrics, 120(1), 341-349. https:// doi.org/10.1007/s11192-019-03114-y

Hicks, D., Wouters, P., Waltman, L., de Rijcke, S., \& Rafols, I. (2015). The Leiden manifesto for research metrics. Nature, 520(7548), 429-431. https://doi.org/10.1038/520429a 
Hook, D. W., Porter, S. J., \& Herzog, C. (2018). Dimensions: Building context for search and evaluation. Frontiers in Research Metrics and Analytics, 3, 23. https://doi.org/10.3389/frma.2018.00023

Lisée, C., Larivière, V., \& Archambault, É. (2008). Conference proceedings as a source of scientific information: A bibliometric analysis. Journal of the American Society for Information Science and Technology, 59(11), 1779-1784. https://doi.org/10.1002/asi.20888

Meo, S. A., Al Masri, A. A., Usmani, A. M., Memon, A. N., \& Zaidi, S. Z. (2013). Impact of GDP, spending on R\&D, number of universities and scientific journals on research publications among asian countries. PLoS ONE, 8(6), 1-8. https://doi.org/10.1371/journal.pone.0066449

Moed, H. F., \& Halevi, G. (2014). Tracking scientific development and collaborations - The case of 25 Asian countries. In David W. Chapman and Chiao-Ling Chien (Ed.), Higher education in Asia: Expanding Out, Expanding Up (pp. 79-92). Retrieved from https://unesdoc.unesco.org/ark:/48223/ pf0000227516

Moed, H. F., Markusova, V., \& Akoev, M. (2018). Trends in Russian research output indexed in scopus and web of science. Scientometrics, 116(2), 1153-1180. https://doi.org/10.1007/s11192-018-2769-8

Moed, H. F., \& Visser, M. (2007). Developing bibliometric indicators of research performance in computer science: An exploratory study. Retrieved from https://www.cwts.nl/pdf/nwo_inf_final_report_v_21020 7.pdf

Mongeon, P., \& Paul-Hus, A. (2016). The journal coverage of web of science and scopus: A comparative analysis. Scientometrics, 106(1), 213-228. https://doi.org/10.1007/s11192-015-1765-5

Montesi, M., \& Owen, J. M. (2008). From conference to journal publication: How conference papers in software engineering are extended for publication in journals. Journal of the American Society for Information Science and Technology, 59(5), 816-829. https://doi.org/10.1002/asi.20805

Nederhof, A. J., van Leeuwen, T. N., \& van Raan, A. F. J. (2010). Highly cited non-journal publications in political science, economics and psychology: A first exploration. Scientometrics, 83(2), 363-374. https ://doi.org/10.1007/s11192-009-0086-y

Nguyen, T. V., \& Pham, L. T. (2011). Scientific output and its relationship to knowledge economy: An analysis of ASEAN countries. Scientometrics, 89(1), 107-117. https://doi.org/10.1007/s11192-011-0446-2

Singh Chawla, D. (2018, December 31). Indonesia's scientists voice concerns about the country's researcher ranking system. Chemical \& Engineering News. Retrieved from https://cen.acs.org/policy/publishing/ Indonesias-scientists-voice-concerns-countrys/96/web/2018/12

Thelwall, M. (2018). Dimensions: A competitor to scopus and the web of science? Journal of Informetrics, 12(2), 430-435. https://doi.org/10.1016/j.joi.2018.03.006

Vanecek, J., \& Pecha, O. (2020). Fast growth of the number of proceedings papers in atypical fields in the Czech Republic is a likely consequence of the national performance-based research funding system. Research Evaluation. https://doi.org/10.1093/reseval/rvaa005

Visser, M., Van Eck, J., \& Waltman, L. (2019). Large-scale comparison of bibliographic data sources: Web of science, scopus, dimensions, and crossref. 17th International Conference on Scientometrics and Informetrics, ISSI 2019 - Proceedings, 2, 2358-2369.

Zhang, L., \& Glanzel, W. (2012). Proceeding papers in journals versus the regular journal publications. Journal of Informetrics, 6(1), 88-96. https://doi.org/10.1016/j.joi.2011.06.007 